\title{
Breast and prostate glands affected by environmental substances (Review)
}

\author{
TAMMY C. BLEAK ${ }^{1}$ and GLORIA M. CALAF ${ }^{1,2}$ \\ ${ }^{1}$ Instituto de Alta Investigación, Universidad de Tarapacá, Arica, Arica 1000000, Chile; \\ ${ }^{2}$ Center for Radiological Research, Columbia University Medical Center, New York, NY 10032, USA
}

Received August 25, 2020; Accepted January 8, 2021

DOI: 10.3892/or.2021.7971

\begin{abstract}
Environmental endocrine disruptor chemicals are substances that can alter the homeostasis of the endocrine system in living organisms. They can be released from several products used in daily activities. Once in the organism, they can disrupt the endocrine function by mimicking or blocking naturally occurring hormones due to their similar chemical structure. This endocrine disruption is the most important cause of the well-known hormone-associate types of cancer. Additionally, it is decisive to determine the susceptibility of each organ to these compounds. Therefore, the present review aimed to summarize the effect of different environmental substances such as bisphenol A, dichlorodiphenyltrichloroethane and polychlorinated biphenyls in both the mammary and the prostate tissues. These organs were chosen due to their association with the hormonal system and their common features in carcinogenic mechanisms. Outcomes derived from the present review may provide evidence that should be considered in future debates regarding the effects of endocrine disruptors on carcinogenesis.
\end{abstract}

\section{Contents}

1. Introduction

2. Data collection method

3. EDCs: BPA, DDT and PCBs

4. Effects of EDCs on mammary gland tissue

5. Effects of EDCs on prostate

6. Conclusions and future perspectives

\section{Introduction}

Endocrine disruptor chemicals (EDCs) are substances that can alter the regular functioning of the endocrine system of living

Correspondence to: Dr Gloria M. Calaf, Instituto de Alta Investigación, Universidad de Tarapacá, 1520 Calle Antofagasta, Arica, Arica 1000000, Chile

E-mail: gmc24@cumc.columbia.edu

Key words: endocrine disruptors, dichlorodiphenyltrichloroethane, bisphenol A, polychlorinated biphenyls, breast and prostate glands organisms $(1,2)$ by interfering with the effect, biosynthesis and metabolism of hormones (3). Consequently, the disruption of hormone homeostasis can affect different physiological processes leading to various diseases in humans (4). Although these compounds can occur naturally, a large number is mainly human-made (5). They can easily reach the environment since they are released from several daily products, such as food cans, metals or pesticides (6), industrial chemicals, organochloride pesticides and other chemicals (3). Due to the massive use of these chemical compounds, they are widely scattered in the environment (7) and are then bio-accumulated by living organisms (8). The principal source of exposure is oral intake of contaminated food (3) and direct contact or inhalation from polluted air (1). Moreover, the possibility of vertical transfer of these compounds through the placenta and breast milk has been reported (6).

It has been observed that EDCs are still present in the environment regardless of their prohibition in some countries; levels of these compounds have been detected in non-pregnant women, pregnant women, men and newborns (9) as a consequence affecting the entire population. Thus, in terms of human health impact (10), these substances have become a priority for international policymakers and the scientific community (11). Unfortunately, once these compounds reach the organism, they can disrupt the endocrine function by mimicking or blocking naturally occurring hormones due to their similar chemical structure (11), therefore affecting the development later in adult life (7).

Regarding the mechanism of action, Fig. 1 shows that EDCs can act through various signaling pathways modulating the action of androgenic thyroid and retinoid receptors, as well as interacting with estrogen receptors (ERs) $(3,7)$ and other non-nuclear receptors, such as membrane ERs, non-steroid receptors and orphan receptors (3). The carcinogenicity attributable to the EDCs is given by genotoxicity, epigenetic modifications or immune system alterations, especially for hormone-associated types of cancer where endocrine disruption is the most relevant cause (12). Therefore, the study and association of EDCs with carcinogenesis are of high priority.

The present review aimed to describe the impact of environmental compounds such as bisphenol A (BPA), dichlorodiphenyltrichloroethane (DDT) and polychlorinated biphenyls (PCBs) on breast and prostate glands. 


\section{Data collection method}

In the present review, a search on MEDLINE (through PubMed: https://pubmed.ncbi.nlm.nih.gov/), Web of Science (https://www.webofknowledge.com) and SCOPUS (https://www.scopus.com/) was conducted between November 2019 and March 2020 to identify studies published from 1982 to the present addressing the association between BPA, DDT, PCBs and carcinogenesis of the breast and prostate glands. The search terms used were 'mammary gland', 'breast cancer', 'prostate gland', 'prostate cancer', 'bisphenol A', 'BPA', 'dichlorodiphenyltrichloroethane', 'DDT', 'polychlorinated biphenyls', 'PCBs', 'exposure', 'epidemiology', 'monotonic response', 'hormone sensitivity' and 'epigenetic', and the data collection approach is shown in Fig. 2.

\section{EDCs: BPA, DDT and PCBs}

First, it has been reported that BPA can interact with ERs due to its chemical structure, thus modulating different signaling pathways (13). Similarly, DDT has been considered as a xenoestrogen compound with estrogen and androgen receptor influence (12). At the same time, PCBs have shown similar action mimicking natural hormones (14) and affecting reproductive development (15). A brief description of each compound is presented below.

BPA is known as a xenoestrogen and can be found in filters, polymers, cosmetics, plasticizers, safety equipment, food cans, thermal paper and medical devices $(5,16,17)$. BPA is popular due to its advantages over other materials such as strength, stability and durability (5). More than 5 million tons of BPA are produced every year (16). BPA can reach living organisms through contaminated food (such as damaged food cans) or water, inhalation or direct contact $(5,10)$. Notably, BPA has been considered a selective ER modulator (10) acting as an estrogen agonist or antagonist depending on the tissue. Consequently, BPA has been implicated in various endocrine disorders, such as infertility, early puberty, metabolic disarrangement and cancer (13).

DDT is a chlorinated hydrocarbon with insecticidal activity; moreover, it was extensively used to control malaria, typhus and other agricultural diseases (18). Due to its physicochemical properties (8), DDT and its metabolites are extremely stable (18). These properties facilitate their bioaccumulation in fatty tissue (8) and their continuous circulation in the environment (19). The main route of exposure to DDT is direct contact or consumption of contaminated food (8). Regardless of the prohibition and restriction of its use in many industrialized countries, DDT and its main metabolite, p,p'-dichlorodiphenyldichloroethylene (DDE), are still present in animals and humans (19). Similarly to BPA, DDT has demonstrated estrogenic properties, either mimicking the estrogen action (20) or blocking the ER activity (19). Additionally, it has been suggested that DDT and its metabolites antagonize the activity of androgens by competitively binding to androgen receptors (ARs) (20).

Finally, PCBs are organochlorine compounds that were extensively used, mainly for industrial purposes (21), until its control and prohibition in the 1970s (1). PCBs consist of a mixture of 209 chlorinated aromatic compounds, known as congeners (15), each with individual properties and action upon the endocrine system. Additionally, it has been reported that these compounds have estrogenic activity, and the interaction with other organochlorines have a synergistic effect (22). According to the toxicological mechanisms of these compounds, they can be divided into two groups: The dioxin-like coplanar PCBs and the non-dioxin-like PCBs. The former are characterized by activating the aryl hydrocarbon receptor (AhR), while the latter interact with nuclear receptors (some of them hormone receptors) and modulate the estrogen and androgen signaling pathways and activate some carcinogenic processes (23). Therefore, considering that hormones regulate numerous types of cancer, it is urgent to investigate the effects of environmental endocrine disruptors and their long-term exposure on hormone-dependent cancers (24). Hence, the present study focuses on two important hormone-associated types of cancer: Breast and prostate cancer (17).

\section{Effects of EDCs on mammary gland tissue}

Exposure at early-life. Since breast tissue is not fully developed at birth, hormones are crucial for its proper and unique development throughout life (25). During this period, cells are under rapid growth and differentiation. Therefore, any exposure to endocrine disruptors at this stage can be critical for breast cancer incidence (26) and denote an important issue that must be addressed by legislators and researchers. Studying different environmental substances with known endocrine-disrupting effects on morphology and human health gives valuable information regarding the consequences. Unfortunately, some of these toxic compounds are still constantly released into the environment despite current regulations. An example of this is the release of DDT from melted glaciers every day; similarly, PCBs accumulated in adipose tissues are released into the body under specific physiologic conditions exerting their effects on the endocrine system (27).

How BPA, DDT and PCBs are associated with carcinogenesis and how they interfere with the normal hormone-tissue response are valid questions in this context. From that perspective, a previous study (28) has suggested that endocrine disruptors directly affect breast cancer incidence; nevertheless, the complete knowledge regarding the immediate association between these environmental toxicants and initiation and progression of cancer remains under investigation. Another study has suggested that in prenatal exposures, BPA interacts with ER inducing the expression of certain genes that cause cellular proliferation, particularly branching ductal growth (26). It is well known that ER is crucial in the carcinogenesis process (29); therefore, any interaction will alter such a process.

Due to its long half-life, DDT accumulates in human tissues, and it has been demonstrated that its metabolites are transferred from breast milk to newborns, thus increasing the serum level in children exposed to such compounds (30). Although a previous study (31) used DDE serum levels as a marker of DDT exposure, design limitations paused the progress regarding conclusive evidence to determine exactly the grade of influence of DDT exposure in early life and breast cancer development. 


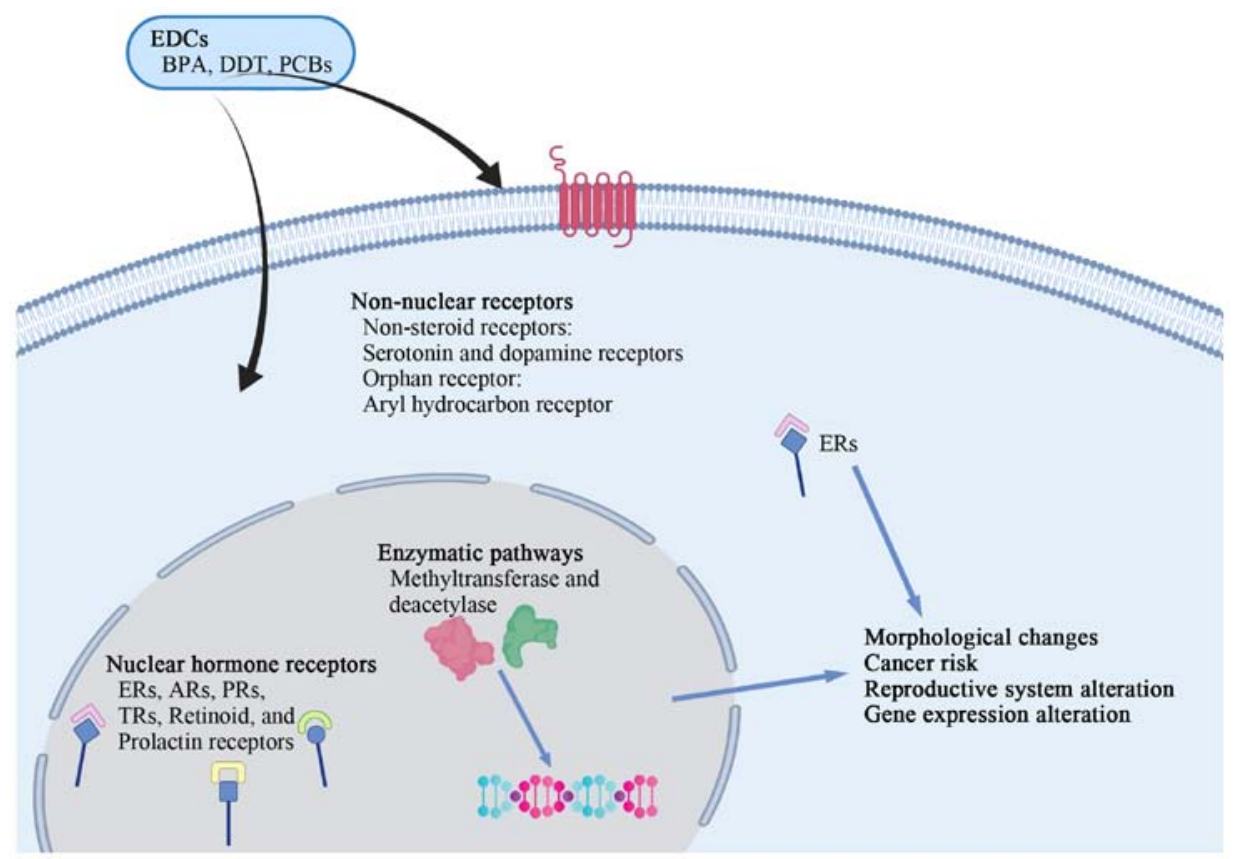

Figure 1. Summary of the mechanism of action of EDCs. BPA, DDT and PCBs can exert their action by modulating different signaling pathways, through the interaction with nuclear hormone receptors, such as ERs, ARs, PRs, TRs, retinoid receptors and prolactin receptors. EDCs can also interact with non-nuclear receptors, such as non-steroid receptors, orphan receptors, membrane ERs and enzymes. EDCs, endocrine disruptor chemicals; BPA, bisphenol-A; DDT, dichlorodiphenyltrichloroethane; PCBs, polychlorinated biphenyls; ERs, estrogen receptors; ARs, androgen receptors; PRs, progesterone receptors; TRs, thyroid receptors.

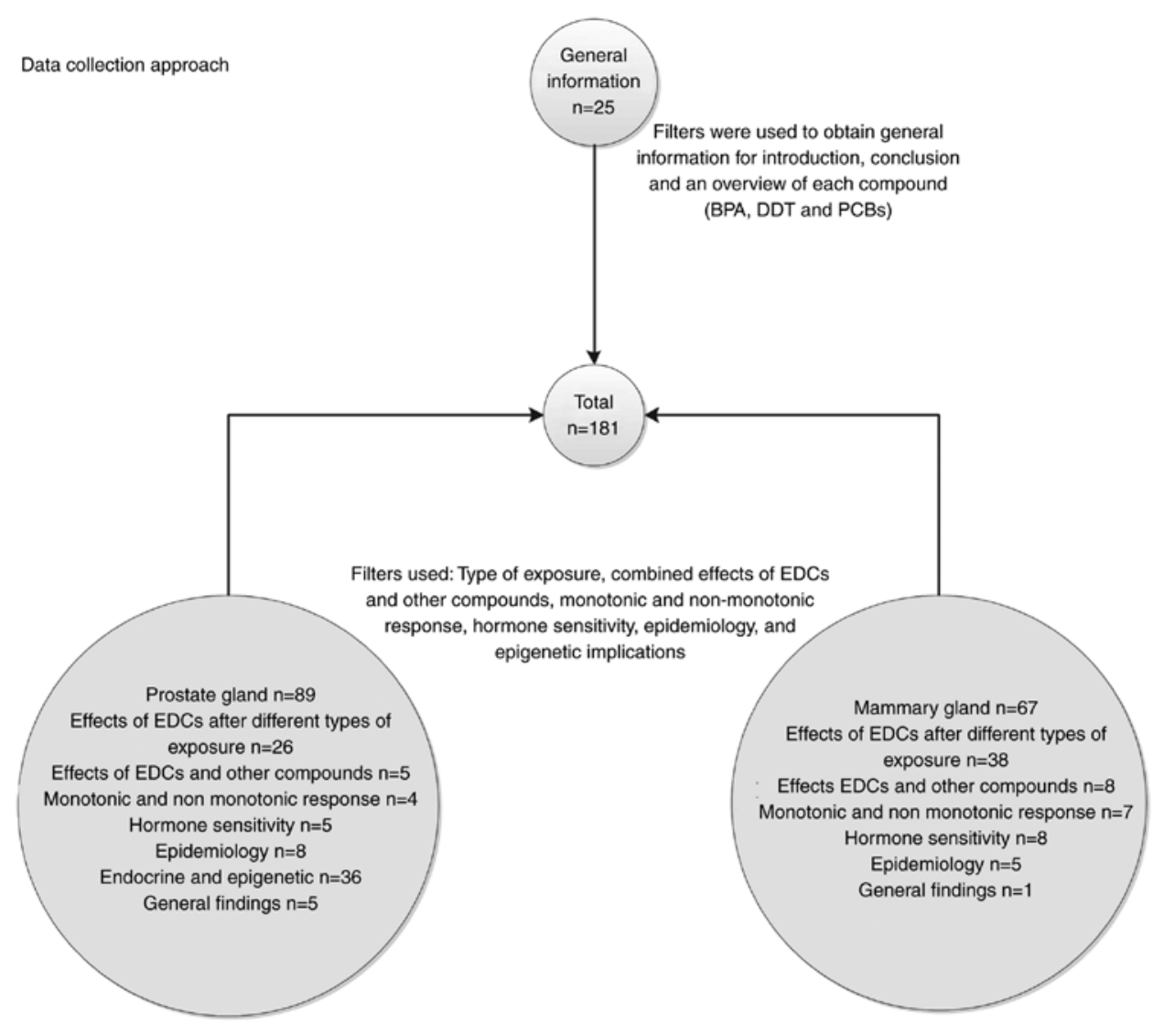

Source of information: PubMed, Web of Sciences, and SCOPUS $n=1404$

Figure 2. Search on MEDLINE (through PubMed), Web of Science and SCOPUS was conducted between November 2019 and March 2020 to identify studies addressing the association between BPA, DDT, PCBs and carcinogenesis of the breast and prostate glands. The search terms used were 'mammary gland', 'breast cancer', 'prostate gland', 'prostate cancer', 'bisphenol A', 'BPA', 'dichlorodiphenyltrichloroethane', 'DDT', 'polychlorinated biphenyls', 'PCBs', 'exposure', 'epidemiology', 'monotonic response', 'hormone sensitivity' and 'epigenetic'. EDCs, endocrine disruptor chemicals; BPA, bisphenol-A; DDT, dichlorodiphenyltrichloroethane; PCBs, polychlorinated biphenyls. 
Regarding the association between early-life PCBs exposure and an increase in breast cancer development, studies are scarce. However, a previous study (32) evaluated whether PCBs concentrations were demonstrative of early-life exposure using a physiologically-based pharmacokinetic (PBPK) model. This evaluation took into consideration some information obtained from the French population-based case-control study (32), and the half-life of PCB153 congener was detected with high frequency in most of the samples used; even though this tool can serve as a predictor of early-life exposure, some hindrances must be considered, for instance, the window of breast cancer susceptibility is not clear for PCB compounds (32). Therefore, it is difficult to establish a direct and close association between PCB compounds and breast cancer when exposed early in life.

Exposure in adults. Paradoxically, as endocrine disruptors disrupt the endocrine function, one of their effects is the derangement of the normal cell interactions (tissue organization). Some interactions, such as the epithelial-epithelial and stromal-epithelial interactions, are fundamental for the definition of any tissue organization, and any change at this level can affect the proper communication with consequences in cell proliferation, motility and cell adhesion (33); therefore, the analysis of these interactions during mammogenesis and carcinogenesis is necessary. It is inevitable not to mention a tissue-based theory, the so-called tissue organization field theory (TOFT) of carcinogenesis; this proposes that morphogenetic fields coordinate histogenesis and organogenesis (33). Then, during the perinatal phase, it leads to tissue arrangement and remodeling processes, affecting morphogenesis; however, this phenomenon can be reversible $(26,34,35)$.

Similarly, it has been reported that BPA affects tissue organization and intensifies the estrogen-tissue-target response, along with the expression of mediators of progesterone, altering the progesterone hormone response (36). Notably, major morphological changes in the mammary gland development were observed when BPA exposure occurred during the embryogenesis phase (37). Moreover, studies have revealed that fetal exposures to BPA cause a more sensitive response to estradiol on certain tissues, such as the uterus, vagina and mammary glands $(25,38)$. Consequently, this leads to mammary gland changes and increases the susceptibility to develop diseases later in life (26).

On the other hand, although DDT has endocrine-disrupting features, its direct effects on cancer remain unknown (39). A previous study that evaluated breast cancer supported the TOFT theory and DDT effects on mammary tissue (34). Concerning DDT and PCBs, the aforementioned study assessed a mixture of different pesticides, including DDT, PCBs and polybrominated biphenyls (PBBs), in normal human breast epithelial cells (34). This evaluation was particularly conducted to determine their effects upon gap junctional intercellular communication in mammary tissue (34). Major effects on intercellular communication integrity in normal epithelial cells were observed after the treatment with the mixture of DDT, halogenated compounds and dieldrin (40). Similar effects were observed in epithelial cells from other tissues under the effects of PCBs $(41,42)$.

Overall, it was suggested that epithelial cell communication was affected by different environmental compounds such as BPA, DDT and PCBs, and the collaboration of individual compounds contributed to this phenomenon (40). In other words, each toxic compound may grant a certain grade of risk to the breast cancer process and other types of cancer. Additionally, to tackle this issue from a broader perspective, other factors such as compound interactions, chemical structure and physiological conditions should be considered.

Exposure during prenatal and postnatal life. In vivo studies that evaluated the long-term effects of BPA based their concentration on the safe reference dose (SRD) provided by the Environmental Protection Agency (EPA) and the United States (US) Food and Drug Administration (USFDA) (29,37). The SRD established for humans is $50 \mu \mathrm{g} / \mathrm{kg} /$ day based on a 1,000-fold reduction of the dose used in the US National Toxicology Program analysis $(29,37)$. Several studies have suggested that early exposure to BPA using doses below the SRD causes different changes at a morphological level, including proliferation, over-growth of structures like terminal end buds (TEBs) and hyperplasia $(37,43)$.

Additionally, it was reported that fetal exposure to low BPA doses affected epithelia-epithelia interactions; for instance, a relevant morphological alteration occurred in fetal mammary tissue after $0.25 \mu \mathrm{g}$ BPA per $\mathrm{kg}^{-1} \mathrm{BW}$ per day ${ }^{-1}$ exposure (38). Different modifications were observed, such as enlargement of ductal area, change in the matrix organization, suppression of lumen formation, abnormal collagen distribution and alteration of the fat pad in the extracellular matrix (44). Moreover, under the influence of BPA, a similar gene expression in stromal and epithelial compartments was observed compared with ethinylestradiol treatment (44). Therefore, this supported the idea of BPA as an endocrine disruptor with xenoestrogen action.

A study was designed to evaluate the effects of BPA in utero exposure in pregnant Sprague Dawley rats, treated with 25 and $250 \mu \mathrm{g} \mathrm{BPA} / \mathrm{kg}$ (45). The measurement of the mammary gland architecture was followed at different ages of the female offspring, and it was observed that morphological components such as TEBs and terminal ducts (TDs), which are epithelial structures, increased at the highest doses of BPA $(250 \mu \mathrm{g})$, and this was time-dependent (45), demonstrating the effects of early exposure to BPA upon the susceptibility to mammary tumor formation.

A previous study (43) also studied the effects of BPA on the female mammary gland at prenatal exposure, reporting an increase in neoplastic lesions, such as ductal hyperplasia, comprising epithelial and stromal alterations near the affected ducts. Notably, the study also observed that most of these effects were not present before puberty, indicating that BPA exerts its influence on estrogen sensitivity, and that there was a notorious presence of mast cells associated with the hyperplastic ducts, suggesting a reinforcement of the angiogenesis process (43).

After perinatal BPA exposure of the mouse mammary gland, some morphological changes were also observed. For instance, mice exposed to BPA from day 8 of pregnancy until day 16 of lactation, with doses $0.25-25 \mu \mathrm{g} \mathrm{BPA} / \mathrm{kg} \mathrm{BW} / \mathrm{d}$ showed a direct correlation between time and increment of alveolar buds (ABs) and intraductal hyperplasia (46). Similarly, in a study where BPA exposure was extended from prenatal to 
postnatal, an increase of ABs was observed at 3 and 9 months of age (26). Notably, the same study also reported that perinatal exposure to estrogens promoted intraductal hyperplasia (26).

Another study used ovariectomized female mice exposed to BPA via osmotic pumps in a concentration of $25-250 \mathrm{ng}$ $\mathrm{BPA} / \mathrm{kg} \mathrm{BW/d}$, from day 9 of pregnancy to postnatal day 4 , reporting an increase in lateral branching, TEBs per ductal area, mammographic density and ABs (47). Other cellular changes, such as an increased number of cells expressing ER and progesterone receptor (PR) in the epithelia, were observed, increasing the sensitivity to these hormones (47).

Another morphological characteristic observed in rodents exposed to BPA was a more fibroblastic and denser stroma near the ducts (48), possibly due to a desmoplastic reaction. Moreover, it was observed that perinatal exposure affects the hormone-tissue response translated into sensitivity to estradiol and overexpression of PR, increasing breast cancer risk $(26,43,47)$.

Furthermore, it was shown that BPA exposure led to paraneoplastic and neoplastic lesions, even in the absence of other carcinogenic compounds $(37,45)$. For instance, Sprague Dawley rats were exposed to different BPA concentrations using osmotic pumps during gestation and postnatal stages, resulting in rats with mini tumors $>1 \mathrm{~cm}^{2}$ after gestational day 9 until postnatal day 21, even when no other carcinogen compound was present (49).

Another study (50) that evaluated the effects of BPA on the mammary gland was performed using non-human primate mammary gland in a model called a 'high-estrogen level model', with some advantages over other rodent models. This model allowed to observe important morphological alterations in the mammary tissue after the in utero BPA exposure, such as epithelial density in monkeys, which is key in breast carcinogenesis (50).

Similarly, DDT has also been investigated in vivo regarding breast cancer (51). However, the results remain inconclusive. In a case-control study performed between 1994 and 1997, it was reported that there was no association between DDE and DDT accumulation and breast cancer risk (51). However, the aforementioned study presented some drawbacks and therefore no definitive conclusions could be stated at that point. Later, a further study involving postnatal and in uterus exposure contributed to investigate the effects of DDT exposure (27). The susceptibility to develop breast cancer when exposure occurred in the early stages of life in prospective human studies was evaluated, revealing an association between DDT early-life exposure and breast cancer risk; moreover, this risk was increased (5-fold) when the exposure occurred early in life compared with when it occurred later in life $(27,34)$.

A case-control study in patients with breast cancer in India during 2015-2016 analyzed the serum levels of organochlorine compounds, such as hexachlorocyclohexane (HCH)- $\alpha$, $\beta, \gamma$, endosulfan, DDT and its metabolites, among other compounds (52). This study revealed that the most frequent stage of breast cancer detected was Stage II (36\%), and invasive ductal carcinoma was the most common type (78.6\%) in those patients (52). Additionally, it was found that DDE levels were higher in patients with breast cancer compared with in healthy individuals (52).
Mammographic breast density is considered a marker of breast cancer risk $(28,53,54)$. It is the result of a combination of hormonal activity, and it is important during mammary tissue development, for example during puberty and pregnancy (53). A study conducted to determine whether in utero environmental exposure affected the mammography density provided valuable evidence associating DDT with different morphological changes, and results indicated that p,p'-DDT and DDE were associated with a more sensitive and dense area, while o,p'-DDT with a non-dense area; notably, o,p'-DDT was associated with a dense area in women with a maternal breast cancer history $(53,55)$. Therefore, it is necessary to consider the type of exposure, the timing and the grade of biotransformation suffered from the toxic compound.

PCBs comprise highly halogenated congeners, providing lipophilicity, which allows bioaccumulation in adipose tissue $(24,56)$. Therefore, it is suggested that this bioaccumulation has a causal association with breast cancer risk. To check this possible association, a previous study collected samples from 51 women (ranging from disease-free to metastatic breast cancer), and PCB concentrations were assayed directly from the breast tissue; additionally, the clinical and pathological features were evaluated (24). Notably, the bioaccumulation of PCBs did not show any direct association with breast cancer; however, this bioaccumulation was associated with age, where the more the exposure, the more the quantity of PCBs accumulated in breast tissue (24).

A hospital-based case-control study conducted in Canada evaluated samples from biopsies of 217 breast cancer cases and 213 benign controls (57). A total of 14 PCBs congeners were considered along with 10 other organochlorine deposits in breast adipose tissue (57). The study detected that some congeners, such as PCB105 and PCB118, had a certain connection with high cancer risks, with a high risk even for premenopausal women, while others, such as PCB170 and PCB180, were also higher but with no clear consistency (57).

Furthermore, a case-control study conducted in Connecticut studied the number of 9 PCB congeners in the adipose breast tissue of 490 women (304 cases and 186 controls), suggesting that individual congeners contributed in a particular manner; for instance, PCB156 showed protective properties, while PCB180 and PCB 183 increased the risk of breast cancer (58). According to Wolff et al (59), congeners can be divided into three groups: i) Potentially estrogenic; ii) potentially antiestrogenic and immunotoxic, dioxin-like; and iii) phenobarbital, CYP inducers, biologically persistent. Therefore, PCB156 can be classified in group 2, according to the aforementioned description and another study (60).

Regarding the possible association between PCBs and the risk of breast cancer, a case-control study was conducted in a high-exposed population in eastern Slovakia, analyzing the serum levels of PCB of 24 patients with breast cancer and 88 healthy individuals (60). From this investigation, a poor association between PCB levels and the risk of cancer was observed; by contrast, a positive association was found between DDE and DDT in the breast cancer samples (60). Nevertheless, the authors of the aforementioned study discussed some limitations, such as the collection of insufficient samples gathered and insufficient sample collection time (60). 
Accordingly, another study indicated that PCBs are structure-dependent and supported that each congener contributed in a specific manner and at a certain grade to develop the disease according to its chemical structure (61). Therefore, individual congener evaluation may provide further insight and more understanding regarding its specific biological effects on breast tissue; such evaluation may serve as a preliminary approach to determine breast cancer risk (58). However, it could not be taken as definitive evidence of causality (57) due to some discrepancies (62) in the magnitude of the effect. Besides, other substances that were not evaluated should be considered since they could also exert a certain effect along with PCBs.

Effects of EDCs and other compounds. As aforementioned, the embryo is highly susceptible to any stimulus, especially to chemicals and hormones, and results indicated that BPA prenatal exposure increased the risk of mammary neoplasia under N-nitroso-N-methylurea (NMU) influence; morphologically, a high number of mast cells was observed in the mammary gland stroma (43). Although the uterus is an important organ that protects the fetus from external factors, total isolation is impossible; different routes allow exogenic compounds to reach the organism during developmental phases and consequently different substances can act concomitantly (63). Therefore, the analysis of their effect can give insight regarding these effects on the embryo. A study has been done on mammary gland tumor formation and the influence of another carcinogenic compound, NMU, alongside BPA; NMU is a chemical compound that has been classified by the International Agency for Research on Cancer (IARC) as possibly carcinogenic to humans (63). Another study reported that in utero BPA-exposed animals had a higher number of neoplastic lesions when they were subsequently treated with low doses of NMU (37), reinforcing proliferation and abnormal development, and increasing the risk of developing mammary gland tumors. Furthermore, a reduction in latency time was observed when pregnant mice were exposed to BPA with subsequent female offspring treatment with 7 , 12-dimethylbenz (a) anthracene (DMBA), and similar results were observed in rats, in which the number and size of tumors increased after BPA and DMBA treatment $(64,65)$.

Some studies $(66,67)$ have suggested that flavonoids are protective molecules. Furthermore, some infant supplements contain soy to counteract the effects of contaminants in infants $(66,67)$. Nevertheless, in vivo studies evaluated the effect of flavonoids and a mixture of common contaminants on the mammary gland, such as p,p'-DDT, p,p'-DDE, endosulfan, PCBs and Aldrin $(66,68)$. The quantities administered were in the range of safety, according to the Agency for Toxic Substances and Disease Registry or the US EPA. Sprague-Dawley rats, 9-16 days of gestation and following postnatal feeding, were administered genistein at $10 \mu \mathrm{g} / \mathrm{g} \mathrm{BW} / \mathrm{d}$. After 200 days of age, the rats exposed perinatally to the mixture and the naturally occurring estrogenic compounds acquired ductal hyperplasia, lactational changes and fibrosis $(66,68)$. It is important to consider that it was suggested that, inversely, prepubertal genistein exposure was associated with a protective action against mammary tumors (66).

Another study in rats revealed that acute pubertal exposure to diethylstilbestrol, genistein and o,p'-DDT can increase mammary cell proliferation and enhanced mammary gland differentiation, especially in TEBs (69). The same study demonstrated that Aroclor 1221, Aroclor 1254 and 2,3,7,8-tetrachlorodibenzo- $p$-dioxin (TCDD) did not show any significant difference compared with the control (69). This may be due to inadequate dose, weak anti-estrogenic properties or wrong exposure timing.

Other examples showed the effects of a mixture of compounds compared with a single compound. For instance, a group of neonate rats fed with a mixture of DDT, DDE and 19 PCB congeners was compared with a group exposed to TCDD alone, and both groups were injected with a cancer-initiator, NMU $30 \mathrm{mg} / \mathrm{kg} \mathrm{BW/d} \mathrm{(70).} \mathrm{Mammary}$ tumors were extracted when they reached the size of $\sim 1 \mathrm{~cm}$ or at 308 days of age, and observations indicated that TCDD and high doses of the mixture induced mammary tumors (70).

Monotonic and non-monotonic response. Hormones, exogenous estrogens and oral contraceptives are known factors that increase breast cancer risk (56). It may be hypothesized that high doses of these factors may increase the risk of breast or other types of cancer, but this is not always the case for EDCs. Similar to some hormones, in vitro and in vivo data demonstrated that EDCs responded to a non-monotonic dose-response $(28,37,45,71)$. Some notable results about non-monotonic and ER expression were obtained in a study conducted on Chinese women (28). Exposure to PCBs was measured in breast adipose tissues of 230 women undergoing a biopsy, lumpectomy or mastectomy: First, PCB153 was detected with the highest molar concentrations compared with the other six congeners that were evaluated; second, postmenopausal women presented the highest levels of PCBs compared with premenopausal women; and third, PCB levels were different from ER expression, showing a non-linear change, presumably due to its non-monotonic response curve, the same as E2 behavior, affecting the ER transcription (56). Similarly, a population-based study suggested that DDE increased breast cancer risk at lower doses (25).

After measuring PCBs and other lipophilic-compound concentrations in breast and abdominal adipose tissue, it was found that the amount of compounds in Europe (72) and the Americas was as follows: Organochlorine pesticides $>$ polychlorinated biphenyls $>$ spider mite control $>$ polybrominated diphenylethers $>2,2^{\prime}, 4,4^{\prime}, 5,5^{\prime}$-he xabromobiphenyl (OCPs $>$ PCBs $>$ SMCs $>$ PBDEs $>$ PBB153, respectively). PCBs (73) and DDTs were $\sim 70 \%$ of the concentration of the total analyzed (74), whereas in Asia, DDT and $\mathrm{HCH}$ were found in high concentrations in adipose tissue (75-77).

These studies established an association between abdominal adipose tissue and breast fat tissue regarding PCBs and other lipophilic contaminants with some specific exceptions (73). This approach may be useful for further analysis considering pharmacokinetic tools as the PBPK model, enabling researchers to predict or evaluate breast cancer risk in a retrospective manner. Therefore, time, period of exposure and dosage should be considered in terms of breast cancer susceptibility, in addition to the characteristics of the compound. Since some of them as PCBs are lipid-soluble compounds, their distribution and 
bioaccumulation serve a crucial role in pharmacokinetics and toxicological analysis.

Hormone sensitivity and receptor expression. Hormones are important for the development of tissue architecture (37). Therefore, any change in this normal structure can have serious consequences later in life. Upon hormone influence, the mammary gland undergoes several morphological changes in the stromal and epithelial sections (37). During this period, the mammary tissue is highly responsive to any hormone impairment. On the other hand, hormones such as prolactin, estradiol and progesterone are recognized as important factors involved in breast cancer $(28,78)$. Although estrogen is associated with cancer etiology, it cannot be considered the only cause of this disease; other hormones and factors are necessary to contribute to that process (28).

A previous study in rodents confirmed that BPA exposure during their prenatal phase had a high impact on the proliferative process and $\mathrm{ER} \alpha$ and prolactin expression (48). The same observations were made in both mice and rats, in which BPA increased the sensitivity to estrogen and overexpression of PR $(26,46,47,79)$. Similarly, in utero DDT exposure was evaluated concerning the estrogen sensitivity. Findings revealed that most breast cancer cases were ER- and PR-positive and erbB-2 (HER2)-negative, and that in utero DDT exposure was associated with HER2-positive breast cancer $(27,34,80,81)$. These results were confirmed using MCF-7 cell lines, where HER2, among other oncogenes, was activated by low DDT doses $(82,83)$.

Regarding PCBs and their estrogenic activity, it was demonstrated that some congeners do possess this activity $(84,85)$; presumably, this activity may increase the risk of hormone-responsive cancers. Conversely, the congeners that exhibited anti-estrogenic characteristics may restrain the harmful effects of estrogens (58). In general, PCB congeners with a high content of chlorinated groups exhibited mainly anti-estrogenic effects (84), in contrast to the poorly halogenated ones. However, there are some discrepancies concerning the hormone receptor expression and its sensitivity. For instance, another epidemiological study indicated that DDE increased breast cancer risk with no association with ER and PR status (25). Similarly, PCB congeners showed no positive association with breast cancer and its relation to ER and PR status (78).

Epidemiology. BPA is present in containers and canned food and is thus present in daily activities (86). It has been shown to influence the mortality rate and reduction of fetal survival (86). Therefore, epidemiological studies and animal studies are necessary to establish a positive and reliable association beyond the molecular aspects of the effects of EDCs. This may encourage epidemiologists and scientists to improve their methods, work together and exert a serious movement to harden public policies regarding environmental toxicants. Several epidemiological studies $(86,87)$ have been performed in the Americas, Asia and Europe, but no direct association has been found between DDT and DDE and breast cancer. However, the influence on the risk of breast cancer at early age exposure cannot be excluded (87).

To evaluate the influence of PCBs in breast cancer survival, a population-based cohort study was performed by collecting blood samples from women diagnosed with first primary invasive or in situ breast cancer between 1996 and 1997 (88). Notably, the analysis was separated for each congener, knowing that each compound had different estrogenic activity. Therefore, anti-estrogenic and persistent congeners such as PCB118 and those part of Group2A (59) were inversely associated with all-cause mortality, in contrast to congeners that clearly showed estrogenic activity, such as PCB174 and PCB177, and were potentially estrogenic and persistent (88). Another study aimed to investigate mortality incidence after a breast cancer diagnosis, providing information regarding the inverse association between PCBs and mortality, particularly in those cases with adverse prognostic factors (89). The study was conducted prospectively and evaluated the adipose concentration of PCBs in Danish women. A slow metabolism could explain this inverse association, where high lipid concentration meant slow metabolization by CYP450, which showed anti-apoptotic effects in vitro (89). Additionally, lipophilic properties may also partly explain the quantities found in adipose tissue, higher than circulating PCBs (89). Similarly, in Canada, Woolcott et al (90) observed that organochlorines were regularly associated with tumors with poor prognosis (ER- and PR-negative, large size and advanced grade), while there was no association with ER status. Therefore, higher levels of organochlorides may be associated with a higher level of aggressiveness of the tumor. An evaluation performed by the IARC concluded that despite the bias and discrepancies, the possible association between PCBs and breast cancer risk cannot be discarded (84).

General findings. Regardless of the route, type or time of exposure, BPA has been reported to alter mammary gland morphology and gene expression (26), and has been associated with breast cancer risk upon early exposure (5). In general, PCBs do not show a positive correlation with breast cancer risk; therefore, larger studies are required to identify a consistent association, even though the concentration of these compounds has decreased due to the prohibited or regulated policies use (74).

To assume that exposure to endocrine disruptors is not a social or economic issue does not comprehensively approach the problem. For instance, the association between DDT exposure and the risk of breast cancer is associated with emerging countries, while developed countries have stricter policies regarding pesticides and hence their population is better protected $(20,52,91)$.

\section{Effects of EDCs on prostate}

Exposure at early-life. Considering that embryo development is highly vulnerable to environmental toxicants (10), any exposure to substances such as BPA, DDT or PCBs may affect the correct morphological development of the prostate. It was reported that neonatal exposure to EDCs was associated with obstruction of male reproductive organs (10) and even dysregulation of some prostate cancer (PCa)-associated genes (4).

The prostate is part of the reproductive male system (92), and like the mammary gland, it is sensitive to external factors such as environmental contaminants, especially during critical windows of development (7). Prostate malfunction affects 
primarily elderly males compared with younger cases $(93,94)$. $\mathrm{PCa}$ is one of the primary causes of cancer-associated deaths among American men (95) and in western countries (5). Additionally, benign prostatic hyperplasia is the most common benign neoplasia among older men (95).

$\mathrm{PCa}$ is associated with different risk factors, including genetics, infection, diet and hormone impairment (5). Age is fundamental in this context, considering that changes in the biological endocrine system are more common at an advanced age (17). Moreover, older men present a higher estrogen/testosterone intra-prostatic ratio and higher ER overexpression compared with young men, and an autopsy study revealed that the prevalence of pathological benign lesions such as hyperplasia increased markedly in $90 \%$ of men older than 80 years old (5).

Studies reported that BPA exerted prostate toxicity $(10,17)$, causing physiological changes at the fetal, pubertal and adult stages $(96,97)$, affecting male fertility (10) and causing hormonal disruption inducing benign hyperplasia and prostate cancer in adults and elderly men (5). Additionally, it was reported that low doses of BPA induced cellular proliferation of the ventral prostate and promoted the synthesis of prostaglandin D2 in adult rats $(5,98)$ via its estrogenic activity. Furthermore, other EDCs are involved in PCa. For example, PCB-153 congener and DDE were observed in the plasma of patients with $\mathrm{PCa}(5)$ and were associated with PCa risk $(8,21)$.

A previous study (9) provided an in vitro human-prostate model from embryonic stem cells in an attempt to simulate in utero conditions; prostate organoids were carefully grown and differentiated with growth factors, steroids and testosterone. Organoids developed branches creating a complex network of epithelial-like ducts confined by a membrane and stromal cells similar to the human prostate (9). Using this model, and during differentiation under BPA exposure (1 or $10 \mathrm{nM}$ ), a disruption of prostate morphogenesis and cell homeostasis was observed in prostate structures in a dose-dependent manner (99), providing evidence in vitro that BPA caused an impaired development in the human fetal prostate that affected maturing prostate structures. In another study (100), cells obtained from the prostate gland of healthy young men, expressing ER $\alpha$ and $\beta$, were transplanted for eventual tissue formation into a kidney-capsule mouse model. When mice were treated with testosterone and estradiol, the in-develop tissue showed improper development, followed by prostatic intraepithelial neoplasia $(100,101)$. On the other hand, a de novo generation study provided evidence to hypothesize that prostate cells may behave like breast tissue and that early embryonic BPA exposure may affect prostate development by increasing hormone susceptibility (9).

Tyl et al (102), in a two-generation study, identified BPA as a non-reproductive selective compound at any dose in mice. On the other hand, the abnormal prostate stem cell self-renewal caused by BPA in early-life exposure, particularly during development, could be considered as an important risk factor for cancer in adulthood (5). Gestational, postnatal and epidemiological studies suggested that during decisive windows of development, exposure to EDCs affected the normal function and increased the risk of PCa in adult life $(95,103,104)$. Some of the points of these studies are presented in the current review.
Exposure in adults. Benign prostatic hyperplasia (BPH) is a non-malignant growth of the prostate gland, affecting older men (17,31). A study based on epithelial-mesenchymal transition (EMT) induction by BPA determined that this substance promoted BPH in aged rats via EMT (17). Sprague-Dawley SD rats (male, 5-7 weeks old) were administered BPA in smaller doses than those indicated by the USFDA (105). Results indicated that BPA promoted the growth of the dorsolateral prostate, increasing the incidence of prostate epithelial tumors (17). Additionally, the ventral prostate lobe became more sensitive to low doses with long-term exposure, and an increase of the estrogen to androgen ratio was observed (17). Even though protein expression suggested an association between BPH and EMT, the specific signaling pathway requires to be studied in detail for further confirmation.

BPA exposure has been associated with obesity and endocrine/metabolic disease (106). A histopathological study confirmed that long-term BPA exposure and a high-fat diet induced lesions typical of proliferative and inflammatory processes; additionally, some metabolic changes altered the normal prostatic function (107). The dorsolateral lobe was the most affected, showing a high number of lesions in rats administered with BPA and a diet rich in fatty acids, suggesting an additive effect (107). In general, BPA increased the number of epithelial alterations and inflammatory foci, and adding a hypercaloric diet affected similar signaling pathways (107). No data were found regarding PCBs and DDT concerning specific histological or morphological prostate tissue changes under these compounds.

Exposure during prenatal and postnatal life. A previous study has investigated BPA exposure in utero to evaluate and determine its specific prostate development effects and a possible association with PCa in animals (108). Similarly to the aforementioned flavonoids, melatonin (N-acetyl-5-methoxy-tryptamine) has some prophylactic features. It has been demonstrated that melatonin protected from cellular damage caused by reactive oxygen species (109). Thus, Olukole et al (110) studied the effects of melatonin against the toxicity caused by BPA in adult rodents using prostate-specific antigen (PSA) measurement, revealing that the probability of developing PCa increased after 14 days of low-dose exposure. Furthermore, histopathological alterations of the prostate were similar to those found when in-utero exposure took place (108). Notably, melatonin decreased lesions in the epithelium compartments, tubular atrophy and vascular congestion (110), suggesting a protective function.

In humans, the evaluation of PCa demonstrated that BPA concentration in urine was higher in patients suffering from $\mathrm{PCa}$ than that in healthy individuals, suggesting an association between amounts of BPA circulating in urine and PCa prognosis (5).

Regarding DDT, it was reported that chlorinated hydrocarbons exposure induced mutagenesis in rodents; this provided the first highlights of DDT and its effects on other organs inducing metastatic liver tumors, hepatocarcinogenesis, lymphomas and lung tumors in animals (18). In a feeding study of 25 years, 24 cynomolgus and rhesus monkeys, which are phylogenetically close to humans, were given DDT $(20 \mathrm{mg} / \mathrm{kg}$ ) in the diet for 130 months and held for observation 
until the age of 18-24 years (18). Results indicated that there was evidence of liver and central nervous system toxicity; two neoplastic developments were observed in the dosed cynomolgus monkey group, one case of metastatic hepatocellular carcinoma and one of prostate adenocarcinoma (18). Additionally, it was observed that the rhesus monkeys were the most susceptible to suffer from neurotoxicity, suggesting a difference in the metabolism within these two species of monkeys (18). Therefore, differences such as compound biotransformation, diet, body fat and serum levels should be considered in each analysis.

Regarding DDT and its effects on ERs in vivo, a study conducted in transgenic mice to express a reporter of ER activity (ERE-tkLUC mouse) investigated the transcriptional activity of ERs measured via luciferase induction (19). Engineered male mice (2 months old) were injected intraperitoneally with $100 \mu \mathrm{l}$ DDT and its two isomers p,p'-DDT and o,p'-DDT to reach $\sim 50 \mu \mathrm{g} / \mathrm{kg}$, a dose high enough to interfere with normal fertility in animals; after measuring the luciferase signal at different periods, it was observed that DDT isomers could modulate ER activity of the reproductive tissue (prostate) and other tissues, such as the liver, brain and thymus (19). Additionally, DDT effects were observed at $16 \mathrm{~h}$, almost $10 \mathrm{~h}$ after the estradiol injection response, presumably due to the kinetic distribution of DDT and derivative compounds (19). These observations show that DDT exerts an effect even at postnatal exposure and that other organs may be affected in time, similarly to the effects observed in mammary tissue after long-term exposure to DDT (18).

Another perspective is the analysis of the epigenetic transgenerational inheritance of epimutations caused by DDT. DNA methylation of sperm is one of these epimutations (111). It was reported that maternal and paternal outcross of the fourth generation caused pathologies in the male prostate, kidney and other abnormalities such as obesity; in particular, DDT lineage animals in the third generation presented prostate disease inherited through mother-of-origin; similarly, kidney disease was transmitted via parent-of-origin (111). However, the aforementioned effects were exhibited by DDT as well as by its main metabolite, DDE. A study conducted in Sprague-Dawley rats demonstrated that in utero, lactation and direct exposure to DDT, DDE and a mixture composed of DDT, deltamethrin, p-nonylphenol and phytoestrogens harmed the male reproductive system, as well as affected the male offspring (7). At concentrations typically found in malarial areas of South Africa, an increment of prostate mass was observed in DDT exposed rats; other abnormalities were observed in other treated groups, such as increased steroid hormone in serum (7), indicating that long-term exposure to pesticides, such as DDT that has a long half-life, is detrimental for living organisms.

On the other hand, it was observed that high levels of DDE in serum induced alterations of the reproductive process in humans (112-114). Exposure to pesticides was demonstrated to be a hindrance to male fertility. This was evaluated in the semen of fertile and infertile men in India. After chemical analysis, an association was found between DDT metabolites, DDE and 1,1-dichloro-2,2 bis(p-chlorophenyl) ethane (DDD) and infertility in Indian men (115). Several mechanisms have been postulated, including alteration of quality and quantity of sex gland secretion, chemical infiltration to seminal plasma affecting the sperm or alteration of the ova at the time of conceptus (116).

Another typical mechanism to evaluate $\mathrm{PCa}$ evolution is the measurement of biochemical recurrence after prostatectomy. Blood levels of 326 men were evaluated for chlordecone, DDE and PCB-153 concentrations at the time of diagnosis; notably, DDE and PCB-153 outcomes were not conclusive concerning the association with elevated PSA levels (117). These results support the fact that determining the net effect of EDCs on $\mathrm{PCa}$ is difficult due to the estrogenic and androgenic modulation by DDE on the prostate and the multiple effects of each congener in the case of PCBs, being troublesome to predict or establish causality of $\mathrm{PCa}$ initiation and progression.

Effects of EDCs and other compounds. BPA was banned in some developed countries, and it was replaced by other analogs such as bisphenol-F, bisphenol-B and bisphenol-S (BPS) (118). BPS is a more stable compound, thus more resistant to degradation than BPA (119). It was reported that the prostate in gerbils presented some morphological particularities (120-122). Silva et al (119) assessed the effects of the BPA analogs on the prostate of gerbils. A total of 30 male gerbils (90 days old) were divided into three groups of 10 animals each and were orally administered with either the dilution vehicle alone (control), $40 \mu \mathrm{g} / \mathrm{kg}$ BPA or $40 \mu \mathrm{g} / \mathrm{kg}$ BPS for 28 days (119). Changes in prostatic tissue, glandular hyperplasia, AR and ER $\alpha$ immunostaining and augmented cell proliferation were observed in the prostate, and neither BPA nor BPS caused changes in testosterone and estradiol serum levels (119).

Another notable combination is DDT and its metabolite DDE; as in breast cancer, this combination also affected the normal functioning and structure of the prostate (8). Moreover, it partly affected the clinical diagnosis and eventual course of the disease due to late treatment (8). Additionally, low quantities of DDT or DDE were able to repress PSA at the mRNA and protein levels; consequently, the PSA test came out altered (8), giving a false negative result for patients with PCa. The specific mechanism was described as blocking the AR binding to the PSA promoter via conformational changes to the AR-ligand complex; therefore, detection of PSA alone should not be regarded as a unique screening detection procedure. Additionally, it was observed that these compounds altered the response of androgen-sensitive cells in traditional therapies (8).

On the other hand, to determine the effects of different environmental pollutants, researchers from Singapore studied the association of several organohalogen compounds and their association with PCa risk (21). The levels of OCPs, PCBs and halogenated flame retardants were measured in a hospital-based case-control study in patients with PCa between 50 and 83 years old; among the pollutants, the combination of DDT and PCBs was more associated with PCa risk, especially for p,p'-DDE, p,p'-DDD, p,p'-DDT, PCB-153 and PCB-138 (21). Inversely, other researchers estimated that proper $\mathrm{PCa}$ risk evaluation should be performed by analyzing specific pesticides, thus establishing their potential association (20). Therefore, a systematic meta-analysis review of different case-control and cohort studies published up to March 2015 
was performed, and no association was found after pooling the results; nevertheless, the authors did not discard the possibility of an association between different OCPs, basing this assumption on factors such as the small number of studies analyzed, heterogeneity between the studies, experiment design and methodology used to evaluate the exposure (20).

Monotonic and non-monotonic response. It was proposed that EDCs possessed a non-traditional dose-response dynamic (20), giving u-shaped curves, exerting higher effect at low doses (3). The biphasic dose-response of BPA was demonstrated in rodent prostate (123), and the combination with ER led to an increase of ER expression, promoting cell proliferation, as in breast cells. Moreover, low-dose and chronic exposure greatly altered the homeostasis of stem cells in rats (124). Controversially, other studies suggested that the effects on adult prostate were dose-dependent $(102,124)$. Therefore, it is difficult to establish a conclusion.

Regarding DDT behavior, an epidemiological study revealed that an analysis performed by separating different contaminants allowed to detect specific associations of compound-effect; however, any possible effect related to the mixture could be unrecognized (20). In a case-cohort study, PCBs, along with OCPs, were evaluated, revealing that PCBs were associated with PCa risk (125) and that long-term exposure to low-doses of the contaminant increased the risk in the normal population (126).

Hormone sensitivity and receptor expression. Similarly as in breast cancer, the influence of hormones should not be underestimated in PCa. It was observed that BPA alone was not enough to induce a prostate pathology, but it increased the prostate susceptibility to estrogen, thus contributing to carcinogenesis later in life; however, rats exposed to BPA in developmental phases with subsequent testosterone and estradiol treatment showed more relevant results (16), suggesting a possible synergy to induce prostate carcinogenesis (92).

In a previous study, after rats were treated with BPA, it was observed that the estrogen to androgen ratio increased, promoting the proliferation of dorsolateral prostate, upregulating ER $\alpha$ and AR with an eventual EMT occurrence (17). Moreover, it was reported that low doses of estrogen could stimulate prostate hyperplasia in rats (127), suggesting its influence upon BPH (17), which was aggravated by higher BPA doses. Thus, this supported the association between BPA influence on sensitive-hormone tissue and its effects on prostate pathology.

Another study evaluated the effects of BPA on adult rats, despite the knowledge that aged rats were prone to develop prostate hyperplasia, and revealed an upregulation of ER $\alpha$ in adult rats (92). A molecular study observed that BPA treatment upregulated the pituitary tumor transforming gene 1, epidermal growth factor, Sh3kbp I and PCNA (92) involved in cell growth and proliferation. Moreover, BPA exposure modified several other molecular elements including enzymes involved in histone modification, such as methyltransferase and deacetylase, in addition to other epigenetic alterations (5). BPA alone was not enough to initiate PCa, but it was suggested that early-life exposure to BPA might serve as an initiator in estrogen-sensitive tissue through epigenetic programming of a set of genes that act upon tumorigenesis later in life $(124,128)$.

On the other hand, it was observed that DDT affected predominantly reproductive tissues in mice, such as testis and prostate, over lung or liver tissues; additionally, it was observed that the DDT mobilization process from fat deposits during fasting or certain diseases or caloric restriction was sufficient to cause ER $\alpha$ modulation at different physiological levels (129). Moreover, modulation of ER and AR by DDT and its metabolite DDE has been suggested; however, final effects upon prostate and eventual causality of $\mathrm{PCa}$ remain hard to determine $(20,130,131)$.

Epidemiology. Although PCa is the most common type of cancer in men in North America, its etiology remains unclear, with age, ethnicity, hormone status, diet and lifestyle being some of the known risk factors $(12,132)$. The evaluation of current treatments is crucial for patients with extremely invasive cancer, since conventional treatments are not fully effective due to resistance to these cytotoxic therapies $(133,134)$. One of the standard treatments is androgen deprivation therapy, which is based on the androgen-dependence of the tumor; this deprivation is reversed by BPA, which activates ARs highly expressed in $\mathrm{PCa}$ (135). Consequently, the resistance to certain prostate therapy is aggravated by the exposure to substances that revert the therapeutic action, affecting the survival of patients.

Based on the high number of farmers affected by PCa, a case-control study to determine the cumulative exposure to pesticides was conducted in British Columbia (12). Through a questionnaire (Job Exposure Matrix) and histological sample evaluation, it was determined that DDT was among the pesticides with a high significance and PCa risk (12).

A retrospective analysis in two Caribbean islands determined that environmental factors were highly associated with the risk of developing $\mathrm{PCa}$, confirmed by the detection of p,p'-DDE serum concentration. It was observed that evaluating over one generation with similar ethnicity and geographical area, the outcomes were different (132). This difference was based on genetic and environmental factors. Another observation was that countries that normally presented low $\mathrm{PCa}$ incidence rates, such as Asia, presented a rise later; this phenomenon might be due to lifestyle (132) where the diet was probably the major external factor that changed. Therefore, preventive-protective medical advice became fundamental in the population, especially for pregnant women and children (136).

In contrast to the studies that have reported a significant correlation between the plasma levels of PCBs and PCa $(137,138)$, a nested case-control study with a total of 14,203 Japanese men (40-69 years old) was conducted, revealing no correlation in the incidence of $\mathrm{PCa}$ for any of the PCBs congeners (137). Similar results were obtained from another case-control study conducted in Canada between 1997 and 1999, in which PSA and digital rectal examinations were performed in men aged 50-80 years old. Participants who took hormone-related medication were excluded, and it was revealed that long-term low-dose exposure to PCBs did not contribute to PCa risk (138). Factors such as differences in exposure, lifestyle or exposure to other substances could 
contribute to this discrepancy. Additionally, it was reported that plasma measurements did not represent real biological effects on the organism and were less significant for those effects that occurred during important periods of development $(137,138)$. Finally, it is necessary to consider that not all PCBs have the same metabolism, meaning that some can circulate longer in the body compared with other environmental compounds (139).

Endocrine disruptor and epigenetic changes. Epigenetic changes involve inheritable alterations of gene expression that do not involve the DNA sequence modification (140). The gene expression is then altered by changes in the chromatin structure due to histone modifications or DNA methylation (141). These changes are catalyzed by epigenetic regulatory enzymes, including DNA methyltransferases, histone methyltransferases and histone deacetylases (141). In general, epigenetics is the connection between genetics and environment in modulating the physiological functions $(142,143)$. The association between epigenetic alterations and tumor development and progression has recently gained more support, and it has been suggested that these epigenetic alterations are given by the mutation of the epigenetic regulatory enzymes $(144,145)$. Endocrine disruptors disrupt the normal endocrine function, as well as the epigenome in a transgenerational manner, especially at early life exposure (146).

On the other hand, it has been reported that the endocrine system interacts with the same modifying enzymes, particularly via nuclear steroid receptors at a certain level (147). Regarding prostate diseases, $\mathrm{PCa}$ or $\mathrm{BPH}$ incidence has increased presumably due to exposure to environmental compounds causing epigenetic transgenerational changes (148). EDCs, such as BPA, produce epigenetic changes in the prostate at early exposure (5). BPA affects directly prostate stem and progenitor cells, causing the epigenetic alterations and thus promoting carcinogenetic occurrence (99,149-151).

A previous study (124) has suggested that BPA influences the predisposition of prostate cells to hormonal sensitivity in adult life through these epigenetic changes. Perinatal prostate exposure to low doses of BPA generates epigenetic alteration as hypo- or hyper-methylation of DNA $(4,152,153)$, histone methylation (154) and changes in the expression levels of non-coding RNAs (149). These changes under estrogen influence can intensify the estrogenic response (124). Another consideration is that estrogen and BPA exposure cause epigenetic modifications on the same genes, possibly altering similar signaling pathways associated with carcinogenesis at early gland development $(5,152)$. Both are involved in the alteration of protein expression, such as that of the histone deacetylase SIRT1 and the histone methyltransferase SET8, which are associated with altered gene expression in PCa cells (155). Therefore, these epigenetic changes are mediated by BPA, and this influence has been reported to occur in a dose-responsive manner (124), possibly through changes in the activity of DNA methyltransferases, methyl-CpG binding domain proteins and histone methyltransferases $(153,154)$.

Additionally, BPA or estradiol alters the expression of enzymes, such as the histone deacetylase SIRT1 and the histone methyltransferase SET8, both associated with PCa gene alterations (155). High levels of estradiol together with
BPA can intensify prostate carcinogenesis and progression $(4,37,149,152-154,156)$. Thus, BPA can be considered as a compound that initiates epigenetic alteration in prostate cells, increasing the risk of cancer, which is then intensified in the presence of estrogen (128). The germline-mediated epigenetic transgenerational inheritance has been reported as a consequence of environmental substances $(157,158)$. These changes are described as the transference of epigenetic information through generations when the exposition to environmental toxicants is not present (159). In particular, DDT was shown to induce the epigenetic transgenerational inheritance of diseases such as obesity, testis disease, ovary disease, kidney disease and prostate disease (160). An analysis of the signaling pathways affected by DDT exposure during fetal gonadal development and the epimutation-gene alteration (DNA methylation, non-coding RNA and histone retention) revealed that pathways associated with cancer and endocytosis were present at the transgenerational F3 generation sperm (161). Moreover, it has been reported that long non-coding RNAs (IncRNAs) are part of the memory regulation via chromatin remodeling, DNA methylations or histone modifications (162). Consequently, DDT ancestral exposure has been shown to result in a differentiation of lncRNAs expression in sperm of males through the germline-mediated epigenetic transgenerational inheritance (161). Therefore, DDT can be considered as a compound with long-term effects via epigenetic modifications, causing changes that can eventually be involved in carcinogenesis in organs such as the prostate. However, future investigations should further explore the role of DDT and epigenetic changes in primordially inducing prostate diseases.

On the other hand, early exposure to PCBs induces epigenetic modulations closely associated with steroid receptors, which in turn serve as cofactors of histone remodeling enzymes (163). Although it is known that most PCBs (particularly the dioxin-like compounds) activate the AhR, these compounds can also cause epigenetic effects by changing the activity of DNA methyltransferases in the liver of the offspring of rats (164). Casati et al (163) have reported that steroid receptors serve as cofactors of histone remodeling enzyme, via PCBs-AR-Jaridlb (a demethylase enzyme) interaction. PCBs interact with specific sites of the ligand-binding domain of the AR (165). Presumably, Jaridlb modulates the AR ligand interaction, and it has been reported that in PCa Jaridlb interacts with AR particularly in the AR transcriptional activity (166). One element that allows the binding of AR/Jarid1b on the target gene is the presence of the androgen-responsive elements and a specific binding site for Jaridlb (PLU1) on the DNA (163). However, the exact mechanism of these interactions remains unclear.

In general, it can be postulated that exposure to EDCs can interact directly in the endocrine system through steroid receptors, which in turn will affect carcinogenic processes via epigenetic mechanisms, altogether with the direct activity of EDCs upon the epigenetic regulatory enzyme, producing epimutations that will be translated into long term transgenerational effects (167).

General findings. The absence of familial history in some epidemiological studies affected the proper association 
between prostate disease incidence and carcinogenetic effects of compounds. As aforementioned, other external factors, such as diet, can affect prostate lesions (107). Thus, further in vivo studies are required to establish the underlying molecular mechanisms (107). Therefore, it is highly recommended to consider diet and resting time as risk factors. Besides time and route of exposure (168), genetics and even ethnicity should be considered (95), since they have been associated with the incidence of developing PCa. Although the mechanism by which EDCs affect prostate carcinogenesis remains unclear, it is clear that one single pathway is not responsible for all outcomes obtained from in vitro and in vivo studies. In this context, another consideration is that some EDCs exhibited synergistic action through the same signaling pathways, while others could activate different pathways (169).

During the present review, some drawbacks were detected. For example, some animal models can be resistant to endocrine disruptors (37). The type of organs to be analyzed can provide biased information depending on when the sample was taken, too early in some cases, therefore limiting tumor initiation (37). Time of exposure is critical in early-life stages when development is crucial (24).

Since the influence of other environmental compounds was inevitable (169), an important limitation in epidemiological investigations is to associate a particular compound with a specific morphological change, apart from associating a specific compound with a single and particular cancer. Similarly, in vivo studies may serve as an approximation, but not as definitive conclusions. However, these studies may provide valuable information regarding structural changes due to exposure to EDCs.

Some of the disadvantages present in most epidemiological studies involve the single sample consideration, which does not reflect real-life long-term exposure (20), time of exposure to EDCs $(170,171)$. In most epidemiological studies, late exposure is analyzed, ignoring the effects of early-stage exposure. Other differences, such as statistical methodology and duration of sample collection, represent an obstacle when analyzing and comparing epidemiological studies (20).

In general, the analysis of different environmental pollutants is not easy. Its complexity lays in the difference between the compounds and the organ-specific features. At a glance, it was possible to mention that exposure to any contaminant was a risk factor. When exposed to a mixture of substances, it is also necessary to understand and consider the biological point of when the exposure occurred, particularly if the exposure took place in a window of susceptibility, since that is when organs such as the prostate and mammary glands are under development, thus increasing their vulnerability $(53,172)$.

On the other hand, it is important to determine the susceptibility of each organ to different environmental EDCs. For instance, some compounds, such as DDT, affected reproductive organs as well as other organs, including the liver, brain and thymus (19). Thus, there was an urgency to study prostate and breast cancer as a whole, with more integrative models (172) to understand the real effects of these compounds on specific organs fully.

Although one study supported a time-dependent response, indicating that the longer the exposure, the higher the risk (46), some compounds exhibited non-monotonic dose behavior. In living organisms, being exposed to a mixture of environmental toxicants does not facilitate the prediction of changes and effects with precision. Additionally, some in vitro and in vivo studies showed additive, synergistic or inhibitory effects $(7,12,66)$. Due to the high number of chemicals involved in the exposure during their evaluation in epidemiological studies, it became difficult to determine the association of one specific environmental compound to a specific tissue (12). Moreover, another study indicated that exposure to a single compound did not reflect the effects that the exposure of a mixture of EDCs could cause, having a significant physiological effect (7). Thus, studies with multiple EDCs combined and different dosages should understand and observe significant physiological effects. This is even more urgent for those compounds with long half-lives, which can be present and exert their long-term effects on humans.

It is highly recommended to consider various elements, including time of exposure, dose-effect (66), tumor susceptibility, target tissue, type of exposure (53), the association with factors such as hormones and exposure to other compounds at different concentrations, to evaluate morphological changes in human mammary and prostate glands. Particularly, BPA showed a certain limit of biotransformation in the liver (37). Therefore, it is crucial to consider whether the exposure occurred during liver development in any specific species.

Concerning PCBs, individual evaluation is required, considering the total universe of 209 congeners to determine the type of sample and type of measurement that may affect results, For instance, it was reported that PCB measurements in adipose tissue, blood level and serum were different, affecting the net outcomes (58). Thus, to state that PCBs are carcinogenic or to determine their effects on any particular tissue, it is necessary to have more data; despite a large number of epidemiological studies, there is still a lack of correspondence among them. This may be due to the contribution of each congener and their different quantities in a mixture $(56,84)$, and to difficulties in identifying the critical window of exposure (89). Therefore, this could affect a particular population differently after exposure. Thus, the type of cancer would depend on a specific feature, such as the molecular structure, metabolites and estrogenic activity.

Concerning DDT, animal studies may be used to confirm the effects of EDCs on humans due to the high correlation among them. Therefore, results from animal and epidemiological studies should be considered by policymakers (34). Species variation is another factor that should be considered when DDT or any compound is evaluated. For instance, similar effects after DDT exposure were detected in monkeys and rats, including tremors and neurotoxicity; nevertheless, hamsters did not show the same effects, and within the same monkey family, differences in metabolisms were present across species (18).

\section{Conclusions and future perspectives}

Despite a large amount of evidence, the consequences of EDCs on human health remain under debate (169). The resultant evidence of animal studies may not be enough for some researchers or legislators. Therefore, additional 


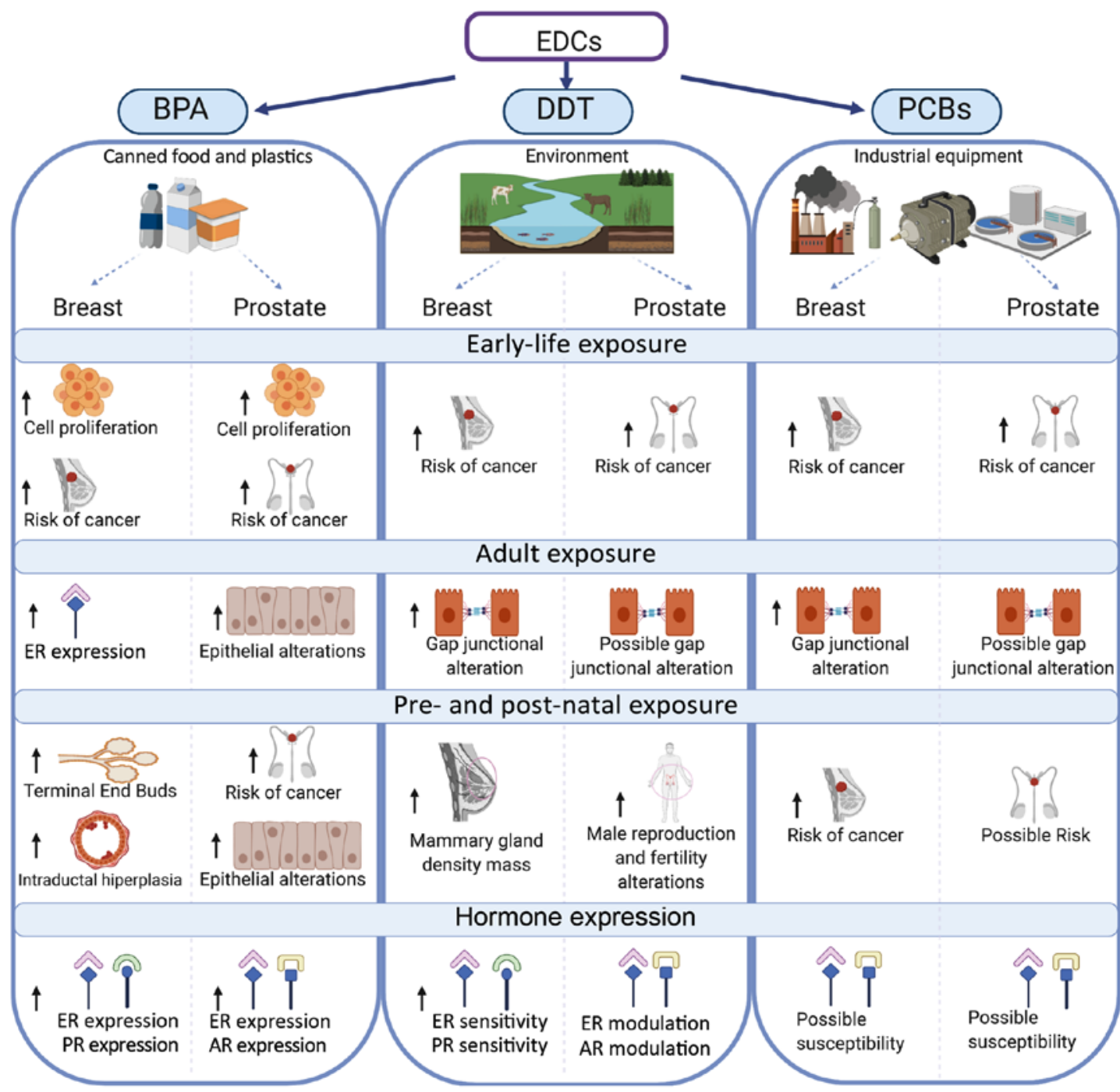

Figure 3. Effect of EDCs on breast and prostate glands after early-life exposure, adult exposure and pre- and post-natal exposure. The effects of EDCs upon estrogen, progesterone and androgen hormone sensitivities are shown. EDCs, endocrine disruptor chemicals; BPA, bisphenol-A; DDT, dichlorodiphenyltrichloroethane; PCBs, polychlorinated biphenyls; ER, estrogen receptor; AR, androgen receptor; PR, progesterone receptor.

epidemiological studies are required to address and establish a direct effect of these contaminants on cancer initiation (95). These studies should also involve multiple-dose analysis and other factors, such as body weight, diets, time of exposure, age, hormone levels and lifestyle.

It can be concluded that contaminants classified as EDCs are still circulating in water, sediments and soil affecting the human mammary and prostate glands (Fig. 3). BPA exposure can induce cell proliferation, morphological alterations and alter carcinogenesis in both glands. Furthermore, BPA, DDT and PCBs contribute to the risk of cancer particularly in mammary and prostate glands, in which postnatal exposure to DDT induces male infertility.

Since hormone-associated cancers are presented, it is imperative to mention that both BPA and DDT affect the expression and sensitivity of the ER and prolactin receptor in the mammary gland, and of AR in the prostate gland.

This phenomenon is caused by the indiscriminate use of these compounds and their lipophilic nature (21). Even though some manufacturers claim their products to be BPA-free (119), BPA analogs are not part of the regulatory frame. Consequently, the overuse of 'healthy-safe products' has been overlooked and should be addressed by public health agencies.

Considering that most of the referred compounds modulate estrogenic activity, a possible substance may be proposed to treat the effects of EDCs such as BPA, DDT and PCBs. Compounds of the selective estrogen receptor modulators category, such as tamoxifen, toremifene and clomifene, should be studied to assess whether their implication in the estrogen signaling pathway is affected by these EDCs. However, it must be considered that EDCs, such as BPA and PCB congeners, can have estrogen and antiestrogen effects depending on the tissue.

Finally, the use of pesticides can be approached from a socio-economical perspective since some epidemiological studies have demonstrated high concentration levels of PCPs in developing countries with no or partial regulations, such as countries in Africa, Asia and Latin America (20,173). These studies suggest that regulation and control in the use of these compounds may contribute to decreasing either the exposure or the development of cancer or of other associated diseases in humans. 


\section{Acknowledgements}

The authors would like to thank Mr. Leodán A. Crispin (Instituto de Alta Investigación, Universidad de Tarapacá, Arica, Chile) for providing technical support.

\section{Funding}

The current study was supported by grants from Convenio de Desempeño (grant no. UTA1117) and from Universidad de Tarapacá and Fondo Nacional de Ciencias (grant no. 1200656).

\section{Availability of data and materials}

Not applicable.

\section{Authors' contributions}

TCB and GMC assessed the authenticity of all the raw data, wrote, edited and reviewed the manuscript and agreed to be accountable for all aspects of the revision in ensuring that the accuracy or integrity of any part of the work was appropriately conducted. TCB and GMC read and approved the final manuscript.

\section{Ethics approval and consent to participate}

Not applicable.

\section{Patient consent for publication}

Not applicable.

\section{Competing interests}

The authors declare that they have no competing interests.

\section{References}

1. Rattan S, Zhou C, Chiang C, Mahalingam S, Brehm E and Flaws JA: Exposure to endocrine disruptors during adulthood: Consequences for female fertility. J Endocrinol 233: R109-R129, 2017.

2. Sifakis S, Androutsopoulos VP, Tsatsakis AM and Spandidos DA: Human exposure to endocrine disrupting chemicals: Effects on the male and female reproductive systems. Environ Toxicol Pharmacol 51: 56-70, 2017.

3. Diamanti-Kandarakis E, Bourguignon JP, Giudice LC, Hauser R, Prins GS, Soto AM, Zoeller RT and Gore AC: Endocrine-disrupting chemicals: An Endocrine Society scientific statement. Endocr Rev 30: 293-342, 2009.

4. Cheong A, Zhang X, Cheung YY, Tang WY, Chen J, Ye SH, Medvedovic M, Leung YK, Prins GS and Ho SM: DNA methylome changes by estradiol benzoate and bisphenol A links early-life environmental exposures to prostate cancer risk. Epigenetics 11: 674-689, 2016.

5. Di Donato M, Cernera G, Giovannelli P, Galasso G, Bilancio A, Migliaccio A and Castoria G: Recent advances on bisphenol-A and endocrine disruptor effects on human prostate cancer. Mol Cell Endocrinol 457: 35-42, 2017.

6. WHO/UNEP: State of the science of endocrine disrupting chemicals-2012: An assessment of the state of the science of endocrine disruptors prepared by a group of experts for the United Nations Environment Programme (UNEP) and WHO. 2012. https://www. who.int/ceh/risks/cehemerging2/en/. Accessed January 2020.

7. Patrick SM, Bornman MS, Joubert AM, Pitts N, Naidoo V and de Jager C: Effects of environmental endocrine disruptors, including insecticides used for malaria vector control on reproductive parameters of male rats. Reprod Toxicol 61: 19-27, 2016.
8. Wong LI, Labrecque MP, Ibuki N, Cox ME, Elliott JE and Beischlag TV: p,p'-Dichlorodiphenyltrichloroethane (p,p'-DDT) and $\mathrm{p}, \mathrm{p}^{\prime}$-dichlorodiphenyldichloroethylene (p,p'-DDE) repress prostate specific antigen levels in human prostate cancer cell lines. Chem Biol Interact 230: 40-49, 2015.

9. Ho SM and Tam NN: Organoid model shows effect of BPA on prostate development. Nat Rev Urol 12: 658-659, 2015.

10. Cariati F, D'Uonno N, Borrillo F, Iervolino S, Galdiero G and Tomaiuolo R: 'Bisphenol a: An emerging threat to male fertility'. Reprod Biol Endocrinol 17: 6, 2019.

11. EPRS: Endocrine disruptors: An overview of the latest developments at the European level in the context of plant protection products. EuropeanParliamentary Research Service:Brussels,EuropeanUnion. 2019. https://www.europarl.europa.eu/thinktank/en/document. html?reference=EPRS STU(2019)631743 'Accessed' February 2020.

12. Band PR, Abanto Z, Bert J, Lang B, Fang R, Gallagher RP and Le ND: Prostate cancer risk and exposure to pesticides in British Columbia farmers. Prostate 71: 168-183, 2011.

13. Konieczna A, Rutkowska A and Rachon D: Health risk of exposure to Bisphenol A (BPA). Rocz Panstw Zakl Hig 66: 5-11, 2015.

14. Gregoraszczuk EL, Rak A, Ludewig G and Gasinska A: Effects of estradiol, PCB3, and their hydroxylated metabolites on proliferation, cell cycle, and apoptosis of human breast cancer cells. Environ Toxicol Pharmacol 25: 227-233, 2008.

15. McGovern V: PCBs are endocrine disruptors: Mixture affects reproductive development in female mice. Environ Health Perspect 114: A368-A369, 2006.

16. Prins GS, Hu WY, Xie L, Shi GB, Hu DP, Birch L and Bosland MC: Evaluation of Bisphenol A (BPA) exposures on prostate stem cell homeostasis and prostate cancer risk in the NCTR-sprague-dawley rat: An NIEHS/FDA CLARITY-BPA consortium study. Environ Health Perspect 126: 117001, 2018.

17. Huang DY, Zheng CC, Pan Q, Wu SS, Su X, Li L, Wu JH and Sun ZY: Oral exposure of low-dose bisphenol A promotes proliferation of dorsolateral prostate and induces epithelial-mesenchymal transition in aged rats. Sci Rep 8: 490, 2018.

18. Takayama S, Sieber SM, Dalgard DW, Thorgeirsson UP and Adamson RH: Effects of long-term oral administration of DDT on nonhuman primates. J Cancer Res Clin Oncol 125: 219-225, 1999.

19. Di Lorenzo D, Villa R, Biasiotto G, Belloli S, Ruggeri G, Albertini A, Apostoli P, Raviscioni M, Ciana P and Maggi A: Isomer-specific activity of dichlorodyphenyltrichloroethane with estrogen receptor in adult and suckling estrogen reporter mice. Endocrinology 143: 4544-4551, 2002.

20. Lewis-Mikhael AM, Olmedo-Requena R, Martinez-Ruiz V, Bueno-Cavanillas A and Jimenez-Moleon JJ: Organochlorine pesticides and prostate cancer, is there an association? A meta-analysis of epidemiological evidence. Cancer Causes Control 26: 1375-1392, 2015.

21. Pi N, Chia SE, Ong CN and Kelly BC: Associations of serum organohalogen levels and prostate cancer risk: Results from a case-control study in Singapore. Chemosphere 144: 1505-1512, 2016.

22. Safe S: Hydroxylated polychlorinated Biphenyls (PCBs) and Organochlorine Pesticides as Potential Endocrine Disruptors, in The Handbook of Environmental Chemistry: Endocrine Disruptors-Part I. Vol. 3 Series: Anthropogenic Compounds, M. Metzler. Springer, Heidelberg, pp155-167, 2001.

23. Pěnčíková K, Svržková L, Strapáčová $S$, Neča J, Bartoňková I, Dvořák Z, Hýžd’alová M, Pivnička J, Pálková L, Lehmler HJ, et al: In vitro profiling of toxic effects of prominent environmental lower-chlorinated PCB congeners linked with endocrine disruption and tumor promotion. Environ Pollut 237: 473-486, 2018.

24. Ellsworth RE, Mamula KA, Costantino NS, Deyarmin B, Kostyniak PJ, Chi LH, Shriver CD and Ellsworth DL: Abundance and distribution of polychlorinated biphenyls (PCBs) in breast tissue. Environ Res 138: 291-297, 2015.

25. Brody JG and Rudel RA: Environmental pollutants and breast cancer. Environ Health Perspect 111: 1007-1019, 2003.

26. Soto AM, Brisken C, Schaeberle C and Sonnenschein C: Does cancer start in the womb? altered mammary gland development and predisposition to breast cancer due to in utero exposure to endocrine disruptors. J Mammary Gland Biol Neoplasia 18: 199-208, 2013.

27. Cohn BA, La Merrill M, Krigbaum NY, Yeh G, Park JS, Zimmermann L and Cirillo PM: DDT exposure in utero and breast cancer. J Clin Endocrinol Metab 100: 2865-2872, 2015. 
28. Wang Z, Liu H and Liu S: Low-dose bisphenol a exposure: A seemingly instigating carcinogenic effect on breast cancer. Adv Sci (Weinh) 4: 1600248, 2016.

29. Marchese S and Silva E: Disruption of 3D MCF-12A breast cell cultures by estrogens-an in vitro model for ER-mediated changes indicative of hormonal carcinogenesis. PLoS One 7: e45767, 2012.

30. Verner MA, Chevrier J, Ngueta G, Rauch S, Bornman R and Eskenazi B: Early-life exposure to p,p'-DDT and p,p'-DDE in South African children participating in the VHEMBE study: An assessment using repeated serum measurements and pharmacokinetic modeling. Environ Int 119: 478-484, 2018.

31. Cohn BA: Developmental and environmental origins of breast cancer: DDT as a case study. Reprod Toxicol 31: 302-311, 2011.

32. Verner MA, Bachelet D, McDougall R, Charbonneau M, Guenel $\mathrm{P}$ and Haddad S: A case study addressing the reliability of polychlorinated biphenyl levels measured at the time of breast cancer diagnosis in representing early-life exposure. Cancer Epidemiol Biomarkers Prev 20: 281-286, 2011.

33. Paulose T, Speroni L, Sonnenschein C and Soto AM: Estrogens in the wrong place at the wrong time: Fetal BPA exposure and mammary cancer. Reprod Toxicol 54: 58-65, 2015.

34. Soto AM and Sonnenschein C: Endocrine disruptors: DDT, endocrine disruption and breast cancer. Nat Rev Endocrinol 11: 507-508, 2015.

35. Soto AM and Sonnenschein C: The tissue organization field theory of cancer: A testable replacement for the somatic mutation theory. Bioessays 33: 332-340, 2011.

36. Ayyanan A, Laribi O, Schuepbach-Mallepell S, Schrick C, Gutierrez M, Tanos T,Lefebvre G, Rougemont J, Yalcin-Ozuysal O and Brisken C: Perinatal exposure to bisphenol a increases adult mammary gland progesterone response and cell number. Mol Endocrinol 25: 1915-1923, 2011.

37. Seachrist DD, Bonk KW, Ho SM, Prins GS, Soto AM and Keri RA: A review of the carcinogenic potential of bisphenol A. Reprod Toxicol 59: 167-182, 2016.

38. Wadia PR, Cabaton NJ, Borrero MD, Rubin BS, Sonnenschein C, Shioda T and Soto AM: Low-dose BPA exposure alters the mesenchymal and epithelial transcriptomes of the mouse fetal mammary gland. PLoS One 8: e63902, 2013.

39. Harada T, Takeda M, Kojima S and Tomiyama N: Toxicity and carcinogenicity of dichlorodiphenyltrichloroethane (DDT). Toxicol Res 32: 21-33, 2016.

40. Kang KS, Wilson MR, Hayashi T, Chang CC and Trosko JE: Inhibition of gap junctional intercellular communication in normal human breast epithelial cells after treatment with pesticides, PCBs, and PBBs, alone or in mixtures. Environ Health Perspect 104: 192-200, 1996.

41. Machala M, Blaha L, Vondracek J, Trosko JE, Scott J and Upham BL: Inhibition of gap junctional intercellular communication by noncoplanar polychlorinated biphenyls: Inhibitory potencies and screening for potential mode(s) of action. Toxicol Sci 76: 102-111, 2003

42. Roehrborn CG: Benign prostatic hyperplasia: An overview. Rev Urol 7 (Suppl 9): S3-S14, 2005.

43. Durando M, Kass L, Piva J, Sonnenschein C, Soto AM, Luque EH and Munoz-de-Toro M: Prenatal bisphenol A exposure induces preneoplastic lesions in the mammary gland in Wistar rats. Environ Health Perspect 115: 80-86, 2007.

44. Vandenberg LN, Maffini MV, Wadia PR, Sonnenschein C, Rubin BS and Soto AM: Exposure to environmentally relevant doses of the xenoestrogen bisphenol-A alters development of the fetal mouse mammary gland. Endocrinology 148: 116-127, 2007.

45. Moral R, Wang R, Russo IH, Lamartiniere CA, Pereira J and Russo J: Effect of prenatal exposure to the endocrine disruptor bisphenol A on mammary gland morphology and gene expression signature. J Endocrinol 196: 101-112, 2008.

46. Vandenberg LN, Maffini MV, Schaeberle CM, Ucci AA, Sonnenschein C, Rubin BS and Soto AM: Perinatal exposure to the xenoestrogen bisphenol-A induces mammary intraductal hyperplasias in adult CD-1 mice. Reprod Toxicol 26: 210-219, 2008.

47. Munoz-de-Toro M, Markey CM, Wadia PR, Luque EH, Rubin BS, Sonnenschein C and Soto AM: Perinatal exposure to bisphenol-A alters peripubertal mammary gland development in mice. Endocrinology 146: 4138-4147, 2005.

48. Murray TJ, Maffini MV, Ucci AA, Sonnenschein C and Soto AM: Induction of mammary gland ductal hyperplasias and carcinoma in situ following fetal bisphenol A exposure. Reprod Toxicol 23: 383-390, 2007.
49. Acevedo N, Davis B, Schaeberle CM, Sonnenschein C and Soto AM: Perinatally administered bisphenol a as a potential mammary gland carcinogen in rats. Environ Health Perspect 121: 1040-1046, 2013

50. Tharp AP, Maffini MV, Hunt PA, VandeVoort CA, Sonnenschein $\mathrm{C}$ and Soto AM: Bisphenol A alters the development of the rhesus monkey mammary gland. Proc Natl Acad Sci USA 109: 8190-8195, 2012

51. Zheng T, Holford TR, Mayne ST, Ward B, Carter D, Owens PH, Dubrow R, Zahm SH, Boyle P, Archibeque S and Tessari J: DDE and DDT in breast adipose tissue and risk of female breast cancer. Am J Epidemiol 150: 453-458, 1999.

52. Kaur N, Swain SK, Banerjee BD, Sharma T and Krishnalata T: Organochlorine pesticide exposure as a risk factor for breast cancer in young Indian women: A case-control study. South Asian J Cancer 8: 212-214, 2019.

53. Krigbaum NY, Cirillo PM, Flom JD, McDonald JA, Terry MB and Cohn BA: In utero DDT exposure and breast density before age 50. Reprod Toxicol 92: 85-90, 2020.

54. Boyd NF, Jensen HM, Cooke G and Han HL: Relationship between mammographic and histological risk factors for breast cancer. J Natl Cancer Inst 84: 1170-1179, 1992.

55. McDonald JA, Cirillo PM, Tehranifar P, Krigbaum NY, Engmann NJ, Cohn BA and Terry MB: In utero DDT exposure and breast density in early menopause by maternal history of breast cancer. Reprod Toxicol 92: 78-84, 20120.

56. He Y, Peng L, Huang Y, Peng X, Zheng S, Liu C and Wu K: Association of breast adipose tissue levels of polychlorinated biphenyls and breast cancer development in women from Chaoshan, China. Environ Sci Pollut Res Int 24: 4778-4790, 2017.

57. Aronson KJ, Miller AB, Woolcott CG, Sterns EE, McCready DR, Lickley LA, Fish EB, Hiraki GY, Holloway C, Ross T, et al: Breast adipose tissue concentrations of polychlorinated biphenyls and other organochlorines and breast cancer risk. Cancer Epidemiol Biomarkers Prev 9: 55-63, 2000.

58. Holford TR, Zheng T, Mayne ST, Zahm SH, Tessari JD and Boyle P: Joint effects of nine polychlorinated biphenyl (PCB) congeners on breast cancer risk. Int J Epidemiol 29: 975-982, 2000.

59. Wolff MS, Camann D, Gammon M and Stellman SD: Proposed PCB congener groupings for epidemiological studies. Environ Health Perspect 105: 13-14, 1997.

60. Pavuk M, Cerhan JR, Lynch CF, Kocan A, Petrik J and Chovancova J: Case-control study of PCBs, other organochlorines and breast cancer in Eastern Slovakia. J Expo Anal Environ Epidemiol 13: 267-275, 2003.

61. Zheng T, Holford TR, Tessari J, Mayne ST, Owens PH, Ward B, Carter D, Boyle P, Dubrow R, Archibeque-Engle S and Zahm SH: Breast cancer risk associated with congeners of polychlorinated biphenyls. Am J Epidemiol 152: 50-58, 2000.

62. Guttes S, Failing K, Neumann K, Kleinstein J, Georgii S and Brunn H: Chlororganic pesticides and polychlorinated biphenyls in breast tissue of women with benign and malignant breast disease. Arch Environ Contam Toxicol 35: 140-147, 1998.

63. IARC: Some inorganic substances, chlorinated hydrocarbons, aromatic amines, $\mathrm{N}$-nitroso compounds, and natural products. IARC Working Group on the Evaluation of Carcinogenic Risks to Humans. Monograph 1. International Agency for Research on Cancer. Lyon, 1972. https://publications.iarc.fr/19 Accessed January 2020

64. Jenkins S, Raghuraman N, Eltoum I, Carpenter M, Russo J and Lamartiniere CA: Oral exposure to bisphenol a increases dimethylbenzanthracene-induced mammary cancer in rats. Environ Health Perspect 117: 910-915, 2009.

65. Jenkins S, Betancourt AM, Wang $\mathrm{J}$ and Lamartiniere CA: Endocrine-active chemicals in mammary cancer causation and prevention. J Steroid Biochem Mol Biol 129: 191-200, 2012.

66. Foster WG, Younglai EV, Boutross-Tadross O, Hughes CL and Wade MG: Mammary gland morphology in Sprague-dawley rats following treatment with an organochlorine mixture in utero and neonatal genistein. Toxicol Sci 77: 91-100, 2004.

67. American Academy of Pediatrics. Committee on Nutrition: American academy of pediatrics. Committee on nutrition. Soy protein-based formulas: Recommendations for use in infant feeding. Pediatrics 101: 148-153, 1998

68. Badger TM, Gilchrist JM, Pivik RT, Andres A, Shankar K, Chen JR and Ronis MJ: The health implications of soy infant formula. Am J Clin Nutr 89 (Suppl 1): 1668S-1672S, 2009.

69. Brown NM and Lamartiniere CA: Xenoestrogens alter mammary gland differentiation and cell proliferation in the rat. Environ Health Perspect 103: 708-713, 1995. 
70. Desaulniers D, Leingartner K, Russo J, Perkins G, Chittim BG, Archer MC, Wade M and Yang J: Modulatory effects of neonatal exposure to TCDD, or a mixture of PCBs, p,p'-DDT, and p-p'-DDE, on methylnitrosourea-induced mammary tumor development in the rat. Environ Health Perspect 109: 739-747, 2001.

71. Welshons WV, Thayer KA, Judy BM, Taylor JA, Curran EM and vom Saal FS: Large effects from small exposures. I. Mechanisms for endocrine-disrupting chemicals with estrogenic activity. Environ Health Perspect 111: 994-1006, 2003.

72. Petreas M, Nelson D, Brown FR, Goldberg D, Hurley S and Reynolds P: High concentrations of polybrominated diphenylethers (PBDEs) in breast adipose tissue of California women. Environ Int 37: 190-197, 2011.

73. Petreas M, Smith D, Hurley S, Jeffrey SS, Gilliss D and Reynolds P: Distribution of persistent, lipid-soluble chemicals in breast and abdominal adipose tissues: Lessons learned from a breast cancer study. Cancer Epidemiol Biomarkers Prev 13: 416-424, 2004.

74. Li AJ, Feldman SM, McNally RK and Kannan K: Distribution of organohalogen and synthetic musk compounds in breast adipose tissue of breast cancer patients in ulster County, New York, USA. Arch Environ Contam Toxicol 77: 68-78, 2019.

75. Kunisue T, Takayanagi N, Isobe T, Takahashi S, Nose M, Yamada T, Komori H, Arita N, Ueda $\mathrm{N}$ and Tanabe $\mathrm{S}$ : Polybrominated diphenyl ethers and persistent organochlorines in Japanese human adipose tissues. Environ Int 33: 1048-1056, 2007.

76. Nakata $H$, Kawazoe M, Arizono K, Abe S, Kitano T, Shimada H, Li W and Ding X: Organochlorine pesticides and polychlorinated biphenyl residues in foodstuffs and human tissues from china: Status of contamination, historical trend, and human dietary exposure. Arch Environ Contam Toxicol 43: 473-480, 2002

77. Tan J, Li QQ, Loganath A, Chong YS, Xiao M and Obbard JP Multivariate data analyses of persistent organic pollutants in maternal adipose tissue in Singapore. Environ Sci Technol 42 2681-2687, 2008

78. Rusiecki JA, Holford TR,Zahm SH and Zheng T: Polychlorinated biphenyls and breast cancer risk by combined estrogen and progesterone receptor status. Eur J Epidemiol 19: 793-801, 2004

79. Jusko TA, Koepsell TD, Baker RJ, Greenfield TA, Willman EJ, Charles MJ, Teplin SW, Checkoway H and Hertz-Picciotto I: Maternal DDT exposures in relation to fetal and 5-year growth. Epidemiology 17: 692-700, 2006.

80. Cohn BA, Wolff MS, Cirillo PM and Sholtz RI: DDT and breast cancer in young women: New data on the significance of age at exposure. Environ Health Perspect 115: 1406-1414, 2007.

81. IBCERCC: Breast Cancer and the Environment: Prioritizing Prevention. National Institute of Environmental Health Sciences \& Interagency Breast Cancer \& Environmental Research Coordinating Committee, USA, 2013. https://www.niehs.nih. gov/about/boards/ibcercc/index.cfm. Accessed January 2020.

82. Enan E and Matsumura F: Activation of c-Neu tyrosine kinase by $o, p^{\prime}-\mathrm{DDT}$ and beta-HCH in cell-free and intact cell preparations from MCF-7 human breast cancer cells. J Biochem Mo Toxicol 12: 83-92, 1998

83. Hatakeyama M and Matsumura F: Correlation between the activation of Neu tyrosine kinase and promotion of foci formation induced by selected organochlorine compounds in the MCF-7 model system. J Biochem Mol Toxicol 13: 296-302, 1999.

84. IARC: Polychlorinated Biphenyls and Polybrominated Biphenyls. Working Group on the Evaluation of Carcinogenic Risk to Humans Monograph 107. International Agency for Research on Cancer. Lyon, 2016. https://www.ncbi.nlm.nih.gov/books/NBK361696/ Accessed November 2018.

85. Plísková M, Vondrácek J, Canton RF, Nera J, Kocan A, Petrik J, Trnovec T, Sanderson T, van den Berg M and Machala M: Impact of polychlorinated biphenyls contamination on estrogenic activity in human male serum. Environ Health Perspect 113: $1277-1284,2005$

86. Ranjit N, Siefert K and Padmanabhan V: Bisphenol-A and disparities in birth outcomes: A review and directions for future research. J Perinatol 30:2-9, 2010.

87. IARC:DDT,Lindane, and 2,4-D. Working Group on the Evaluation of Carcinogenic Risk to Humans. Monograph 113. International Agency for Research on Cancer. Lyon, 2018. https://www.ncbi. nlm.nih.gov/books/NBK507424/ Accessed November, 2018.

88. Parada H Jr, Wolff MS, Engel LS, Eng SM, Khankari NK, Neugut AI, Teitelbaum SL and Gammon MD: Polychlorinated biphenyls and their association with survival following breast cancer. Eur J Cancer 56: 21-30, 2016.
89. Roswall N, Sorensen M, Tjonneland A and Raaschou-Nielsen O: Organochlorine concentrations in adipose tissue and survival in postmenopausal, Danish breast cancer patients. Environ Res 163: 237-248, 2018

90. Woolcott CG, Aronson KJ, Hanna WM, SenGupta SK, McCready DR, Sterns EE and Miller AB: Organochlorines and breast cancer risk by receptor status, tumor size, and grade (Canada). Cancer Causes Control 12: 395-404, 2001.

91. Gray JM, Rasanayagam S, Engel C and Rizzo J: State of the evidence 2017: An update on the connection between breast cancer and the environment. Environ Health 16: 94, 2017.

92. Wu S, Huang D, Su X, Yan H, Wu J and Sun Z: Oral exposure to low-dose bisphenol A induces hyperplasia of dorsolateral prostate and upregulates EGFR expression in adult Sprague-Dawley rats. Toxicol Ind Health 35: 647-659, 2019

93. Liao LM and Schaefer W: Cross-sectional and longitudinal studies on interaction between bladder compliance and outflow obstruction in men with benign prostatic hyperplasia. Asian J Androl 9: 51-56, 2007.

94. Xia SJ, Xu XX, Teng JB, Xu CX and Tang XD: Characteristic pattern of human prostatic growth with age. Asian J Androl 4: 269-271, 2002

95. Prins GS: Endocrine disruptors and prostate cancer risk. Endocr Relat Cancer 15: 649-656, 2008

96. Vom Saal FS: Triennial Reproduction Symposium: Environmental programming of reproduction during fetal life: Effects of intrauterine position and the endocrine disrupting chemical bisphenol A. J Anim Sci 94: 2722-2736, 2016

97. Herath CB, Jin W, Watanabe G, Arai K, Suzuki AK and Taya K: Adverse effects of environmental toxicants, octylphenol and bisphenol A, on male reproductive functions in pubertal rats. Endocrine 25: 163-1672, 2004

98. Wu J, Huang D, Su X, Yan H and Sun Z: Oral administration of low-dose bisphenol A promotes proliferation of ventral prostate and upregulates prostaglandin D2 synthase expression in adult rats. Toxicol Ind Health 32: 1848-1858, 2016.

99. Calderon-Gierszal EL and Prins GS: Directed differentiation of human embryonic stem cells into prostate organoids in vitro and its perturbation by low-dose bisphenol A exposure. PLoS One 10: e0133238, 2015.

100. Cantone I and Fisher AG: Epigenetic programming and reprogramming during development. Nat Struct Mol Biol 20: 282-289, 2013.

101. Prusinski L, Al-Hendy A and Yang Q: Developmental exposure to endocrine disrupting chemicals alters the epigenome: Identification of reprogrammed targets. Gynecol Obstet Res 3 $1-6,2016$.

102. TylRW, Myers CB,Marr MC, Sloan CS,CastilloNP, VeselicaMM, Seely JC, Dimond SS, Van Miller JP, Shiotsuka RN, et al: Two-generation reproductive toxicity study of dietary bisphenol A in CD-1 (Swiss) mice. Toxicol Sci 104: 362-84, 2008.

103. Kilian E, Delport R, Bornman MS and de Jager C: Simultaneous exposure to low concentrations of dichlorodiphenyltrichloroethane, deltamethrin, nonylphenol and phytoestrogens has negative effects on the reproductive parameters in male Spraque-Dawley rats. Andrologia 39: 128-135, 2007.

104. Skakkebaek NE: Endocrine disrupters and testicular dysgenesis syndrome. Horm Res 57 (Suppl 2): S43, 2002

105. USFDA: Bisphenol A (BPA). U.S. Food \& Drug Administration, USA. 2018. https://www.fda.gov/food/food-additives-petitions/bisphenol-bpa. Accessed January 2020.

106. Porreca I, Ulloa-Severino L, Almeida P, Cuomo D, Nardone A, Falco G, Mallardo M and Ambrosino C: Molecular targets of developmental exposure to bisphenol A in diabesity: A focus on endoderm-derived organs. Obes Rev 18: 99-108, 2017.

107. Facina CH, Campos SG, Goncalves BF, Goes RM, Vilamaior PS and Taboga SR: Long-term oral exposure to safe dose of bisphenol A in association with high-fat diet stimulate the prostatic lesions in a rodent model for prostate cancer. Prostate 78: 152-163, 2018

108. Amaral FG, Turati AO, Barone M, Scialfa JH, do Carmo Buonfiglio D, Peres R, Peliciari-Garcia RA, Afeche SC, Lima L, Scavone C, et al: Melatonin synthesis impairment as a new deleterious outcome of diabetes-derived hyperglycemia. J Pineal Res 57: 67-79, 2014.

109. Andrabi SS, Parvez S and Tabassum H: Melatonin and ischemic stroke: Mechanistic roles and action. Adv Pharmacol Sci 2015: 384750,2015

110. Olukole SG, Ajani SO, Ola-Davies EO, Lanipekun DO, Aina OO, Oyeyemi MO and Oke BO: Melatonin ameliorates bisphenol A-induced perturbations of the prostate gland of adult Wistar rats. Biomed Pharmacother 105: 73-82, 2018. 
111. Ben Maamar M, King SE, Nilsson E, Beck D and Skinner MK Epigenetic transgenerational inheritance of parent-of-origin allelic transmission of outcross pathology and sperm epimutations. Dev Biol 458: 106-119, 2020.

112. Cohn BA, Cirillo PM, Wolff MS, Schwingl PJ, Cohen RD, Sholtz RI, Ferrara A, Christianson RE, van den Berg BJ and Siiteri PK: DDT and DDE exposure in mothers and time to pregnancy in daughters. Lancet 361: 2205-2206, 2003.

113. Hruska KS, Furth PA, Seifer DB, Sharara FI and Flaws JA Environmental factors in infertility. Clin Obstet Gynecol 43: 821-829, 2000.

114. Korrick SA, Chen C, Damokosh AI, Ni J, Liu X, Cho SI, Altshul L, Ryan L and Xu X: Association of DDT with spontaneous abortion: A case-control study. Ann Epidemiol 11: 491-496, 2001.

115. Pant N, Mathur N, Banerjee AK, Srivastava SP and Saxena DK Correlation of chlorinated pesticides concentration in semen with seminal vesicle and prostatic markers. Reprod Toxicol 19: 209-214, 2004.

116. Mann T and Lutwak-Mann C: Passage of chemicals into human and animal semen: Mechanisms and significance. Crit Rev Toxicol 11: 1-14, 1982.

117. Brureau L, Emeville E, Helissey C, Thome JP, Multigner L and Blanchet P: Endocrine disrupting-chemicals and biochemical recurrence of prostate cancer after prostatectomy: A cohort study in Guadeloupe (French West Indies). Int J Cancer 146: 657-663, 2020.

118. Rosenmai AK, Dybdahl M, Pedersen M, Alice van Vugt-Lussenburg BM, Wedebye EB, Taxvig C and Vinggaard AM: Are structural analogues to bisphenol a safe alternatives? Toxicol Sci 139: 35-47, 2014.

119. Silva JPA, Ramos JG, Campos MS, da Silva Lima D, de Azevedo Brito PV, Mendes EP, Taboga SR, Biancardi MF, Ghedini PC and Santos FCA: Bisphenol-S promotes endocrine-disrupting effects similar to those promoted by bisphenol-A in the prostate of adult gerbils. Reprod Toxicol 85: 83-92, 2019.

120.Zaviacic M and Ablin RJ: The female prostate and prostate-specific antigen. Immunohistochemical localization, implications of this prostate marker in women and reasons for using the term 'prostate' in the human female. Histol Histopathol 15: 131-142, 2000.

121. Biancardi MF, Dos Santos FC, de Carvalho HF, Sanches BD and Taboga SR: Female prostate: Historical, developmental, and morphological perspectives. Cell Biol Int 41: 1174-1183, 2017.

122. Muto M, Inamura K, Ozawa N, Endo T, Masuda H, Yonese J and Ishikawa Y: Skene's gland adenocarcinoma with intestinal differentiation: A case report and literature review. Pathol Int 67: 575-579, 2017

123. Huang D, Wu J, Su X, Yan H and Sun Z: Effects of low dose of bisphenol $\mathrm{A}$ on the proliferation and mechanism of primary cultured prostate epithelial cells in rodents. Oncol Lett 14 2635-2642, 2017.

124. Prins GS, Ye SH, Birch L, Zhang X, Cheong A, Lin H, CalderonGierszal E, Groen J, Hu WY, Ho SM and van Breemen RB: Prostate cancer risk and DNA methylation signatures in aging rats following developmental BPA exposure: A dose-response analysis. Environ Health Perspect 125: 077007, 2017.

125. Lim JE, Nam C, Yang J, Rha KH, Lim KM and Jee SH: Serum persistent organic pollutants (POPs) and prostate cancer risk: A case-cohort study. Int J Hyg Environ Health 220: 849-856, 2017.

126. Ritchie JM, Vial SL, Fuortes LJ, Guo H, Reedy VE and Smith EM: Organochlorines and risk of prostate cancer. J Occup Environ Med 45: 692-702, 2003.

127. Wu JH, Jiang XR, Liu GM, Liu XY, He GL and Sun ZY: Oral exposure to low-dose bisphenol A aggravates testosterone-induced benign hyperplasia prostate in rats. Toxicol Ind Health 27: 810-819, 2011.

128. Sharma S, Kelly TK and Jones PA: Epigenetics in cancer. Carcinogenesis 31: 27-36, 2010.

129. Villa R, Bonetti E, Penza ML, Iacobello C, Bugari G, Bailo M, Parolini O, Apostoli P, Caimi L, Ciana P, et al: Target-specific action of organochlorine compounds in reproductive and nonreproductive tissues of estrogen-reporter male mice. Toxicol Appl Pharmacol 201: 137-148, 2004.

130. Carruba G: Estrogen and prostate cancer: An eclipsed truth in an androgen-dominated scenario. J Cell Biochem 102: 899-911, 2007.

131. Leavens TL, Sparrow BR and Devito MJ: Lack of antiandrogenic effects in adult male rats following acute exposure to 2,2-bis(4-chlorophenyl)-1,1-dichloroethylene (p,p'-DDE). Toxicology 174: 69-78, 2002.
132. Belpomme D, Irigaray P, Ossondo M, Vacque D and Martin M: Prostate cancer as an environmental disease: An ecological study in the French Caribbean islands, Martinique and Guadeloupe. Int J Oncol 34: 1037-1044, 2009.

133. Zeliadt SB, Ramsey SD, Penson DF, Hall IJ, Ekwueme DU, Stroud L and Lee JW: Why do men choose one treatment over another?: A review of patient decision making for localized prostate cancer. Cancer 106: 1865-1874, 2006.

134. Kirkpatrick JP and Anscher MS: Radiotherapy for locally recurrent prostate cancer. Clin Adv Hematol Oncol 3: 933-942, 2005.

135. Hess-Wilson JK: Bisphenol A may reduce the efficacy of androgen deprivation therapy in prostate cancer. Cancer Causes Control 20: 1029-1037, 2009.

136. Landau-Ossondo M, Rabia N, Jos-Pelage J, Marquet LM, Isidore Y, Saint-Aimé C, Martin M, Irigaray P and Belpomme D; ARTAC international research group on pesticides: Why pesticides could be a common cause of prostate and breast cancers in the French Caribbean Island, Martinique. An overview on key mechanisms of pesticide-induced cancer. Biomed Pharmacother 63: 383-395, 2009.

137. Sawada N, Iwasaki M, Inoue M, Itoh H, Sasazuki S, Yamaji T, Shimazu T and Tsugane S; Japan Public Health Center Based Prospective (JPHC) Study Group: Plasma organochlorines and subsequent risk of prostate cancer in Japanese men: A nested case-control study. Environ Health Perspect 118: 659-665, 2010

138. Aronson KJ, Wilson JW, Hamel M, Diarsvitri W, Fan W, Woolcott C, Heaton JP, Nickel JC, Macneily A and Morales A: Plasma organochlorine levels and prostate cancer risk. J Expo Sci Environ Epidemiol 20: 434-445, 2010.

139. Wolff MS, Zeleniuch-Jacquotte A, Dubin N and Toniolo P: Risk of breast cancer and organochlorine exposure. Cancer Epidemiol Biomarkers Prev 9: 271-277, 2000.

140. Egger G, Liang G, Aparicio A and Jones PA: Epigenetics in human disease and prospects for epigenetic therapy. Nature 429: 457-463, 2004.

141. Han M, Jia L, Lv W, Wang L and Cui W: Epigenetic enzyme mutations: Role in tumorigenesis and molecular inhibitors. Front Oncol 9: 194, 2019.

142. Zhang X and Ho SM: Epigenetics meets endocrinology. J Mol Endocrinol 46: R11-R32, 2011

143. Fleisch AF, Wright RO and Baccarelli AA: Environmental epigenetics: A role in endocrine disease? J Mol Endocrinol 49: R61-R67, 2012.

144. Tatton-Brown K, Seal S, Ruark E, Harmer J, Ramsay E, Del Vecchio Duarte S, Zachariou A, Hanks S, O'Brien E, Aksglaede L, et al: Mutations in the DNA methyltransferase gene DNMT3A cause an overgrowth syndrome with intellectual disability. Nat Genet 46: 385-388, 2014.

145. Cohen AL, Holmen SL and Colman H: IDH1 and IDH2 mutations in gliomas. Curr Neurol Neurosci Rep 13: 345, 2013.

146. Dolinoy DC, Huang D and Jirtle RL: Maternal nutrient supplementation counteracts bisphenol A-induced DNA hypomethylation in early development. Proc Natl Acad Sci USA 104: 13056-13061, 2007

147. Leader JE, Wang C, Fu M and Pestell RG: Epigenetic regulation of nuclear steroid receptors. Biochem Pharmacol 72: 1589-1596, 2006.

148. Klukovich R, Nilsson E, Sadler-Riggleman I, Beck D, Xie Y, Yan W and Skinner MK: Environmental toxicant induced epigenetic transgenerational inheritance of prostate pathology and stromal-epithelial cell epigenome and transcriptome alterations: Ancestral origins of prostate disease. Sci Rep 9: 2209, 2019.

149. Ho SM, Cheong A, Lam HM, Hu WY, Shi GB, Zhu X, Chen J, Zhang X, Medvedovic M, Leung YK and Prins GS: Exposure of human prostaspheres to bisphenol A epigenetically regulates SNORD family noncoding RNAs via histone modification. Endocrinology 156: 3984-3995, 2015.

150. Prins GS, Hu WY, Shi GB, Hu DP, Majumdar S, Li G, Huang K, Nelles JL, Ho SM, Walker CL, et al: Bisphenol A promotes human prostate stem-progenitor cell self-renewal and increases in vivo carcinogenesis in human prostate epithelium. Endocrinology 155: 805-817, 2014.

151. Prins GS, Calderon-Gierszal EL and Hu WY: Stem cells as hormone targets that lead to increased cancer susceptibility. Endocrinology 156: 3451-3457, 2015.

152. Ho SM, Tang WY, Belmonte de Frausto J and Prins GS: Developmental exposure to estradiol and bisphenol A increases susceptibility to prostate carcinogenesis and epigenetically regulates phosphodiesterase type 4 variant 4 . Cancer Res 66: 5624-5632, 2006 
153. Tang WY, Morey LM, Cheung YY, Birch L, Prins GS and Ho SM: Neonatal exposure to estradiol/bisphenol A alters promoter methylation and expression of Nsbpl and Hpcall genes and transcriptional programs of Dnmt $3 \mathrm{a} / \mathrm{b}$ and $\mathrm{Mbd} 2 / 4$ in the rat prostate gland throughout life. Endocrinology 153: 42-55, 2012.

154. Wang Q, Trevino LS, Wong RL, Medvedovic M, Chen J, Ho SM, Shen J, Foulds CE, Coarfa C, O'Malley BW, et al: Reprogramming of the epigenome by MLL1 links early-life environmental exposures to prostate cancer risk. Mol Endocrinol 30: 856-871, 2016.

155. Burton K, Bajdas A, Shaw L and Morey LM: The effect of the estrogenic compounds E2 and BPA on the expression of histone modifying enzymes in two prostate cancer models. FASEB J 28 : 942-944, 2014.

156. Wong RL, Wang Q, Trevino LS, Bosland MC, Chen J, Medvedovic M, Prins GS, Kannan K, Ho SM and Walker CL: Identification of secretaglobin Scgb2a1 as a target for developmental reprogramming by BPA in the rat prostate. Epigenetics 10 : $127-134,2015$

157. Anway MD, Cupp AS, Uzumcu M and Skinner MK: Epigenetic transgenerational actions of endocrine disruptors and male fertility. Science 308: 1466-1469, 2005.

158. Skinner MK: Endocrine disruptor induction of epigenetic transgenerational inheritance of disease. Mol Cell Endocrinol 398: 4-12, 2014.

159. Skinner MK: Environmental epigenetic transgenerational inheritance and somatic epigenetic mitotic stability. Epigenetics 6: 838-842, 2011.

160. Skinner MK, Manikkam M, Tracey R, Guerrero-Bosagna C, Haque $\mathrm{M}$ and Nilsson EE: Ancestral dichlorodiphenyltrichloroethane (DDT) exposure promotes epigenetic transgenerational inheritance of obesity. BMC Med 11: 228, 2013.

161. Skinner MK, Ben Maamar M, Sadler-Riggleman I, Beck D, Nilsson E, McBirney M, Klukovich R, Xie Y, Tang C and Yan W: Alterations in sperm DNA methylation, non-coding RNA and histone retention associate with DDT-induced epigenetic transgenerational inheritance of disease. Epigenetics Chromatin 11: 8, 2018.

162. Yan W: Potential roles of noncoding RNAs in environmental epigenetic transgenerational inheritance. Mol Cell Endocrinol 398: 24-30, 2014

163. Casati L, Sendra R, Poletti A, Negri-Cesi P and Celotti F: Androgen receptor activation by polychlorinated biphenyls: Epigenetic effects mediated by the histone demethylase Jarid $1 \mathrm{~b}$. Epigenetics 8: 1061-1068, 2013.
164. Desaulniers D, Xiao GH, Lian H, Feng YL, Zhu J, Nakai J and Bowers WJ: Effects of mixtures of polychlorinated biphenyls, methylmercury, and organochlorine pesticides on hepatic DNA methylation in prepubertal female Sprague-Dawley rats. Int J Toxicol 28: 294-307, 2009.

165. Portigal CL, Cowell SP, Fedoruk MN, Butler CM, Rennie PS and Nelson CC: Polychlorinated biphenyls interfere with androgen-induced transcriptional activation and hormone binding. Toxicol Appl Pharmacol 179: 185-194, 2002

166. Xiang Y, Zhu Z, Han G, Ye X, Xu B, Peng Z, Ma Y, Yu Y, Lin H, Chen AP and Chen CD: JARID1B is a histone H3 lysine 4 demethylase up-regulated in prostate cancer. Proc Natl Acad Sci USA 104: 19226-19231, 2007.

167. Casati L, Sendra R, Sibilia V and Celotti F: Endocrine disrupters: The new players able to affect the epigenome. Front Cell Dev Biol 3: 37, 2015.

168. Tse LA, Lee PMY, Ho WM, Lam AT, Lee MK, Ng SSM, He Y, Leung KS, Hartle JC, Hu H, et al: Bisphenol A and other environmental risk factors for prostate cancer in Hong Kong. Environ Int 107: 1-7, 2017.

169. Maffini MV, Rubin BS, Sonnenschein C and Soto AM: Endocrine disruptors and reproductive health: The case of bisphenol-A. Mol Cell Endocrinol 254-255: 179-186, 2006.

170. Lopez-Cervantes M, Torres-Sanchez L, Tobias A and Lopez-Carrillo L: Dichlorodiphenyldichloroethane burden and breast cancer risk: A meta-analysis of the epidemiologic evidence. Environ Health Perspect 112: 207-214, 2004.

171. Huang L, Pu Y, Alam S, Birch L and Prins GS: Estrogenic regulation of signaling pathways and homeobox genes during rat prostate development. J Androl 25: 330-337, 2004.

172. Terry MB, Michels KB, Brody JG, Byrne C, Chen S, Jerry DJ, Malecki KMC, Martin MB, Miller RL, Neuhausen SL, et al: Environmental exposures during windows of susceptibility for breast cancer: A framework for prevention research. Breast Cancer Res 21: 96, 2019.

173. Jaga K: What are the implications of the interaction between DDT and estrogen receptors in the body? Med Hypotheses 54: $18-25,2000$.

This work is licensed under a Creative Commons Attribution-NonCommercial-NoDerivatives 4.0 International (CC BY-NC-ND 4.0) License. 